\title{
Peru: Providers' compliance with quality of care norms
}

\author{
Federico R. Leon
}

Population Council

Follow this and additional works at: https://knowledgecommons.popcouncil.org/departments_sbsr-rh

Part of the Demography, Population, and Ecology Commons, Health Services Research Commons, International Public Health Commons, and the Public Health Education and Promotion Commons How does access to this work benefit you? Let us know!

\section{Recommended Citation}

Leon, Federico R. 1999. "Peru: Providers' compliance with quality of care norms," FRONTIERS Final Report. Washington, DC: Population Council. 


\title{
Peru: Providers' Compliance with Quality of Care Norms
}

\author{
by Federico R. León \\ Population Council
}

30 November 1999

Final report of the in-house project "Monitoring family planning providers' compliance with the quality of care norms of Peru's Ministry of Health", conduced from 14 June through 30 September 1999. This study was funded by the U. S. AGENCY FOR INTERNATIONAL DEVELOPMENT (USAID) under the terms of Cooperative Agreement Number HRN-A-00-98-0012-00. The opinions expressed herein are those of the author and do not necessarily reflect the view of USAID. The study was requested by USAID/Peru as part of the activities of its PASARE Program and used Field Support funds.

The study was closely coordinated with the Peru Ministry of Health (Dr. Jorge Parra, Director of Reproductive Health) and USAID/Peru (Dr. Lucy López, Coordinator of the PASARE Program). The following key personnel participated in the study: Guillermo Vallenas, Statistician; Rosa Monge and María Rosa Gárate, Field Coordinators; Alex Ríos, Agustín Espinoza, and Alicia Calderón, Research Assistants; and Ingeborg García and Adriana Zumarán, Interns.

The author wishes to thank Susan Brems, Christine Adamczyk, Ricardo Vernon, Joanne Gleason, John Townsend, and Marge Horn for their support for this project, and John Townsend for his comments on preliminary reports and assistance in discussions with USAID/Peru about the implications of the findings for Tiahrt Amendment requirements. 


\section{Contents}

$\begin{array}{lll}\text { I. INTRODUCTION } & 04\end{array}$

Problem 04

Evaluation Issues $\quad 05$

Program Setting $\quad 07$

Research Objectives $\quad 08$

$\begin{array}{ll}\text { II. METHOD } & 09\end{array}$

Overview 09

Selection of Facilities $\quad 10$

Quality Assurance Decision Rules 11

Service Test 11

Exit and Home Interviews 13

$\begin{array}{ll}\text { III. RESULTS } & 15\end{array}$

Hospitals 15

Health Centers $\quad 24$

Health Posts 34

Reliability 39

Cost and Cost-Effectiveness 41

$\begin{array}{ll}\text { IV. DISCUSSION } & 44\end{array}$

The Observational Evidence $\quad 44$

The Evidence as Reported by Clients 45

Reflections on the Monitoring System 47

$\begin{array}{lll}\text { V. UTILIZATION } & 48\end{array}$

VI. CONCLUSIONS AND RECOMMENDATIONS 49

$\begin{array}{lr}\text { NOTES } & 50\end{array}$

$\begin{array}{lr}\text { ACKNOWLEDGMENTS } & 50\end{array}$

REFERENCES $\quad 51$

APPENDICES

Appendix A. Sampling $\quad 55$

Appendix B. LQAS Methodology $\quad 58$

Appendix C. Training and Supervision of Simulated Clients 60

Appendix D. Training and Supervision of Interviewers 61

Appendix E. Interindividual Variation within Facilities 63

Appendix F. Case Studies $\quad 65$ 


\section{SUMMARY}

The Peru's Ministry of Health $(\mathrm{MOH})$ provides family planning services throughout the country. In March 1998 it introduced changes in its service delivery strategy. Quantitative contraceptive method targets/quotas were eliminated and Voluntary Surgical Contraception (VSC) campaigns forbidden. The $\mathrm{MOH}$ set quality of care goals purported to assure informed choice of methods and respect for the user's reproductive intentions and rights. This study was designed to assess the extent to which providers comply with the guidelines in their daily routine. Three national samples, of urban hospitals and health centers and rural health posts, were obtained $(\mathrm{N}=19$ facilities per sample) and Lot Quality Assurance Sampling rules were used to reach conclusions on the basis of six observations per facility. Primary data collection took place in June-August 1999.

Observations of the provider-client interaction supplied by simulated clients as part of Service Tests specially devised for this project showed that both in health centers and in hospitals the strongest elements of care are those of interpersonal relationships and free choice of methods. Providers treat clients with respect and, in health centers, ensure privacy during client-provider consultations. They inform clients about a variety of contraceptive methods and do not betray any systematic biases in favor or against any particular method or methods. On the other hand, both hospitals and health centers revealed significant shortcomings insofar as screening for contraindications and providing information to clients were concerned (especially pertaining to action mechanisms and method side effects but also to usage instructions). In handling VSC cases at hospitals, providers failed to comply with $\mathrm{MOH}$ standards concerning use of the VSC Request Form and the 72-hour reflection period between last counseling and surgical intervention.

Home follow-up interviews with clients sterilized at hospitals demonstrated that almost all sterilizations are tubal ligations and a majority are performed in the immediate postpartum (a quarter of them following cesarean section). Clients receive counseling before the surgical procedure and choose VSC knowing that they will never have more children. They recall signing at least one form before the surgical procedure (yet not its contents) and being given an appointment to return to the hospital. They are generally satisfied with the services, although some (10 to 24 percent) regret the loss of their reproductive capacity later.

Exit interviews with family planning users at urban health centers primarily sought to establish the extent of their family planning knowledge. Clients know that the injectable is applied every three months and causes menstrual alterations, that the pill is taken every day and failure to do so increases the risk of pregnancy, that sterilized women will not have more children, and that the condom is placed in the penis before intercourse. With respect to the method currently used (mainly the injectable, secondarily the pill), knowledge is limited. Clients know more about its usage instructions and follow-up than about their contraindications or side effects.

Home follow-up interviews with users of rural health posts revealed lesser knowledge but a similar pattern (i.e., greater knowledge concerning usage instructions and follow-up than contraindications or side effects). Rural clients decided on their own to use contraception and selected the family planning method themselves. Providers did not pressure them to choose a given method. 


\section{INTRODUCTION}

\section{A. PROBLEM}

Contraceptive prevalence in Peru has increased systematically since the 1960s. It reached 64 percent in 1996, up from 57 percent in 1991. The calendar rhythm continues to be the leading contraceptive method (18 percent), followed by the IUD (12 percent) and female sterilization (10 percent). Contraceptive prevalence in rural settings was always lower than in urban areas. Currently, it is only 51 percent (Peru-DHS, 1997).

Practically since the inception of the National Population Policy Law 15 years ago, and until very recently, Peru's National Family Planning Program - a division of the $\mathrm{MOH}$ - operated under the dominant assumption that services must be implemented to meet the high unmet need for fertility control revealed by population surveys.

The Program's goals were to be met via individual family planning providers responding to method-specific targets assigned to clusters of facilities. Thus, for instance, the Handbook of Family Planning Norms and Procedures (MOH, 1989, pp. 117-121) presented an example of programming for Western Lima according to which MOH providers should accumulate 19,817 yearly users of periodic abstinence, 16,268 IUD insertions, 11,683 VSC interventions, 10,846 users of the pill, and 6,259 users of barrier or injectable methods. The method targets guided logistical operations and were purported to increase contraceptive prevalence and promote long-acting methods $(\mathrm{MOH}, 1989$, p. 17). The Handbook for Reproductive Health: Methods and Procedures (MOH, 1992) maintained this approach and improved the provider reporting form that fed the national information system with the monthly number of new users and continuers per method (SIS-240). The 1995-2000 Reproductive Health and Family Planning Program (MOH, 1995) set the goal of a prevalence of modern contraceptives equal to 50 for year 2000.

When the Peruvian Congress (1995) approved VSC as a contraceptive method, the MOH recalculated the number of surgical interventions it would have to perform to fulfill the unmet need for sterilizations. Meeting this need became the Program's central objective and more than 71,000 were performed in 1996 and almost 97,000 in 1997, mainly through VSC campaigns ("jornadas"). These were organized by local MOH staff in provincial capitals and other sites, wherein itinerant teams of surgeons and local physicians serviced the waiting women and men. Home visits to enroll sterilization candidates played an important part. For instance, of 376 vasectomized men who were interviewed in Northern Lima in 1998, only 29 percent had visited a service delivery point (SDP) seeking the sterilization. Thirty-five percent had been invited to consider VSC during a health consultation at an SDP and 36 percent had been enrolled at their households (Espinoza et al., 1999).

\section{Method Targets versus Individual Needs of Clients}

In the 1980s and early 1990s, the method targets were not disaggregated into individual provider quotas per provider and the $\mathrm{MOH}$ did not perceive a conflict between its use of methodspecific targets and the concept of individual reproductive rights. The National Program endorsed the International Conference on Population and Development (ICPD) Programme for Action (United Nations, 1994) and stated that servicing clients according to their reproductive needs and intentions was a priority (MOH, 1995). 
Yet, in early $1997 \mathrm{MOH}$ family planning providers of the province of Santa called into question their own ability to provide client-centered services of acceptable quality to users of reversible methods given the burden of demanding sterilization quotas coming from health authorities (Ramos \& Wong, 1997). Observations of the provider-client interaction by simulated clients (Cáceres \& Villanueva, 1997), data from client exit interviews (Salazar \& Rivero, 1997), and focus groups with users of family planning services (Salazar \& Llajamango, 1997) revealed random deficits in the providers' quality of care but did not find systematic biases stressing the choice of specific methods, such as VSC. Hence, León (1997) concluded that the Santa providers were behaving as a buffer or filter between the sterilization quotas and the individual users. However, complaints of coercion exerted by providers eager to sterilize emerged the same year in other areas of the country, some deaths were attributed to VSC; religious, feminist, and human-rights groups intervened, and the crisis exploded in the Peruvian and international media (e.g., CRLP, 1999).

\section{Focus on Informed Choice}

In March of 1998, the MOH (1998a) recognized the problem and introduced several changes. First, some statements in the 1995-2000 Reproductive Health and Family Planning Program (MOH, 1995) were modified to minimize demographic targets and the MOH began to redesign its Counseling Handbook emphasizing the concept of quality of care and, within this concept, method choice and information given to users (Bruce, 1990).

A revised VSC Handbook demanded that all sterilizations be preceded by two counseling sessions, that the interval between the user signature of informed consent and the surgical intervention should not be less than 72 hours, and that the user sign the informed consent form a second time immediately before the surgical procedure. The $\mathrm{MOH}$ initiated a process of certification of SDPs and individual surgeons. Campaigns centered on sterilization were forbidden; all campaigns ought to offer integrated services including all family planning methods, maternal health services, and early prevention of gynecological cancers. Finally, some recommendations for the follow-up of sterilized patients were formulated (MOH, 1998a). More recently, the MOH (1998b) has presented a third version of the VSC Handbook and a consolidated version of all of the Program's family planning delivery norms (MOH, 1999).

One year has elapsed since the inception of these reforms. During this interval, the revised technical handbooks have been made available to trainers, several cohorts of providers have been trained, and a number of SDPs and surgeons have been certified. On the other hand, the rumor that the MOH's Basic Health for Everybody program rejected renewal of contracts to personnel who failed to insert a number of IUDS and/or perform a number of sterilizations never subsided.

\section{B. EVALUATION ISSUES}

Neither the assignment of individual quotas to providers nor the providers' compliance with the quality of care norms during service provision had been assessed systematically at the national level prior to this study. Moreover, the National Family Planning Program lacked a monitoring system capable to provide reliable assessments in this area. 


\section{Monitoring System}

A monitoring system seeking to assess provider compliance with service delivery guidelines ought to be based on observations of the provider-client interaction. This is the arena in which clients are given the option to choose among several methods or, as the critics of the MOH pointed out, wherein coercion can take place.

A study of primary health care carried out in Guatemala in 1994 showed that the observation of provider-client behavior had a better overall balance of measurement sensitivity and specificity than either exit interviews or the revision of medical records (Hermida et al., 1996). Yet the use of direct observers to obtain descriptions of the provider-client interaction interferes with the naturalness of the interaction. According to Miller et al. (1991, p. 141), one of its consequences is the elicitation of maximum performance by the provider instead of his or her typical performance. Trained simulated clients represent a better alternative in this respect (León et al., 1994a). Simulated-client observations have been shown to be more valid as measurements of the normal behavior of health providers than either direct observations or client exit interviews (Franco et al., 1997). The Service Test is an offshoot of simulated client methodology in which the evaluator controls the client profile and hence is able to focus observation on very specific provider behavior (León et al., 1994a, 1994b). This study used the Service Test to assess the quality of care offered by $\mathrm{MOH}$ providers.

Trained simulated clients may supply accurate reports concerning what the provider does or fails to do. However, they can only describe the provider behavior that takes place when the user solicits the services, not when the provider takes the initiative to offer them. Second, a simulated client cannot enter the operating room, receive an sterilization, and report on the provider's surgical and follow-up behavior. Finally, simulated client reports do not encompass the immediate effects of counseling, e.g., do not grasp whether real clients attain the necessary knowledge about the method chosen. Therefore, monitoring systems of family planning delivery need to consider interviews with real users of the services despite the lower validity of their reports. This study used exit interviews and home interviews to assess the quality of care offered by $\mathrm{MOH}$ providers and its immediate effects on clients.

A more fully encompassing system would have had to include interviews with providers as well (Pathak et al., 1998). It is important to know, for example, whether they are given quotas, whether they have in fact been trained, and whether they know and have internalized the norms. Interviews with providers were considered in this project's proposal, which was approved by the Peru MOH and USAID/Peru, but later withdrawn at the request of USAID/Peru.

\section{Sampling Methodology}

A monitoring system requires a sampling methodology, and two alternatives are available in theory. One is the conventional sampling design in which the criteria for defining sample size include the size of he universe, the expected percentage with satisfactory responses, and the desired confidence interval.

The number of SDPs to be observed under this model, however, would have been very high and impossible to reach in a short time. For example, having a universe of more than 6,500 health 
facilities in Peru, an expected percentage of satisfactory behaviors of 80 percent, and a confidence interval of $+/-5 \%$ with an associated probability of .95 , the number of facilities to observe would reach 236, of which many would fall in remote areas. Neither the time nor the financial resources to meet this challenge were available when this study was requested. Hence, we selected a useful but less conventional sampling strategy.

The chosen alternative was Lot Quality Assurance Sampling (LQAS), a practical approach developed in the 1920s as an industrial quality-control sampling procedure that has been recently applied to assess the quality of care in the child survival (Valadez, 1991) and family planning areas (Valadez et al., 1997).

In LQAS, the samples are too small to provide sufficiently narrow confidence intervals under generally accepted standards. Rather than point estimation, LQAS implements hypothesis testing: a decision is made about the quality of a particular lot or sample based on the probability that the number of defective units in the sample selected is less than or equal to some critical value. The hypergeometric distribution, or its normal or binomial approximations, is used to calculate the chances of making type I and type II errors (Lemeshow \& Taber, 1991). Most applications of LQAS in the health area have sought to assess prevalence (e.g., Lemeshow \& Taber, 1991) or coverage (e.g., Lanata \& Black, 1991; Valadez, 1991). This study followed Valadez et al.'s (1997) strategy to assess quality of care in the family planning area and used the binomial distribution.

\section{PROGRAM SETTING}

The $\mathrm{MOH}$ offers integrated reproductive health services throughout Peru by means of 331 hospitals, 1,431 health centers, and 4,827 health posts staffed with physicians, nurse-obstetricians, nurses, and nonprofessional health workers making a total of more than 15,000 individual providers. Hospitals have the highest density of physicians, although they generally share most family planning tasks with nurse-obstetricians and the nurse-obstetricians perform most of the counseling. In the past few years, the MOH's Basic Health for Everybody program staffed health centers and posts rather heavily with nurse-obstetricians. Nonprofessional health workers are most prevalent in health posts and rural areas.

The situation of sterilization in Peru is not well known. Vasectomies are about one tenth of tubal ligations. It is believed that about half of the tubal ligations are performed in the immediate postpartum period at hospitals. On the other hand, a considerable number of vasectomies and interval tubal ligations took place during the mass sterilization campaigns of 1996 and 1997 in which local personnel screened VSC candidates and scheduled appointments for surgery. The sterilizations were performed in short calendar periods (a few days) with help from itinerant groups of surgeons. The sterilization campaigns have subsided since but may have not disappeared.

In early 1999, the $\mathrm{MOH}$ needed to know whether providers were complying with the quality of care norms, to adjust its systems. USAID/Peru needed information to establish whether standards established by the Tiahrt Amendment were being met. 


\section{RESEARCH OBJECTIVES}

- The main objective of this project was to produce an evaluation of provider compliance with current $\mathrm{MOH}$ quality of care guidelines at the national level.

- Secondarily, the project sought to assess the reliability of the various components of the monitoring system.

- A third objective was to assess the cost of implementing each of the components of the monitoring system. 


\section{METHOD}

\section{A. OVERVIEW}

The sampling strategy implemented aimed to simultaneously represent the diverse types of health facilities extant at the national level and apply the various measurement approaches required on practical grounds to meaningfully encompass certain pre-specified themes, tapping both urban and rural client populations.

Table 1. Sample Design of Study

\section{SDPs}

Samples and Instruments

$\underline{\text { Sample II }}$

Service Test Form B

Client Exit Interview

$\underline{\text { Sample I }}$

Service Test Form A

\section{Hospitals Health Centers Health Posts}
$(\mathrm{N}=19)$
$(\mathrm{N}=19)$
$(\mathrm{N}=19)$

$\mathrm{X}$

Follow-Up of Sterilized Women and Men

$$
\mathrm{X}
$$

$\underline{\text { Sample III }}$

Follow-Up of Rural Family Planning Users

$\mathrm{X}$

$\mathrm{X}$

Two types of simulated clients were needed for the Service Test. One was the woman who has used reversible methods and now wants a permanent method (Form A). This Service Test client profile probes provider compliance with the technical norms concerning provision of VSC. The other profile was that of the young woman who has not used modern contraception and must be counseled unbiasedly with respect to the range of methods available at the SDP (Form B). This profile basically probes provider's behavior with respect to method choice and information given about reversible contraceptives and is sensitive to provider coercion. Real clients represented in Service Test client profile A typically receive VSC services at hospitals, whereas those represented in client profile B typically receive family planning services at health centers and posts.

By definition, simulated clients cannot report on the surgical aspects of the sterilization services, and their reports on how they, as clients, made their decision to terminate their 
reproductive capacity are meaningless. This made it necessary to draw a specific sample of sterilized women and men who could report on the surgical aspects of the sterilization services received at hospitals and their decision-making processes retrospectively, whether they took place at antenatal consultations or family planning counseling sessions in non-maternal settings. Neither is the Service Test a good instrument to measure client's knowledge concerning family planning issues. The client exit interview is a more appropriate tool for this endeavor, and health centers are the best sites in which clients can be interviewed. Hospitals receive a large and more homogeneous population of clients, and health posts generally do not have the required daily flow of clients to select clients easily.

Simulated clients can operate unnoticed at large urban SDPs (hospitals or health centers) given the high flow of clients at these facilities and the general anonimity of the user population. At smaller health posts, however, they would be noticed and this could affect the naturalness of the providers' delivery behavior, particularly in rural areas. Even worse is the case of client exit interviews. Interviewers might have to wait weeks until a new family planning client arrives. A more reasonable option to tap the quality of care given at small SDPs in either urban or rural areas is the household survey of users sampled from administrative records. Like the exit interview, the household survey can elicit memories of the provider-client interaction and test current knowledge concerning the contraceptive method chosen.

Therefore, a sample of hospitals was obtained for application of one form of the Service Test and conduct of household interviews with sterilized men and women; a sample of health centers for application of the second form of the Service Test and conduct of exit interviews; and a sample of health posts in rural areas to perform a follow-up of general family planning users (see Table 1).

\section{B. SELECTION OF FACILITIES}

The 6,589 SDPs existing in Peru define the universe of this study. From the user perspective, the relevant unit is the SDP, not the individual provider. The user seeks services from the SDP, which assigns her or him an individual provider. Different providers may be available simultaneously or on different days. What is relevant here is the likelihood that a client seeks services at the SDP. Therefore, SDPs must be weighted for user population and larger SDPs will have greater probabilities of being chosen.

A two-step sampling of SDPs was required owing to the lack of SIS-240 information concerning the user population of individual SDPs at the National Family Planning Program. The Program possessed consolidated information per Reporting Unit, a cluster of SDPs which, depending on the region of the country, may be an SBS (Basic Health System), UBASS (Basic Health Service Unit), UTES (Territorial Health Unit), health network led by a hospital, or even an entire region. One-hundred seventy-two such units reported complete service delivery data in 1998 (plus a clinic at the MOH's headquarters and about 20 Armed Forces facilities, which were not included in this study). The first step in the sampling process consisted of segmenting the 172 large units into three size categories according to the number of sterilizations performed in 1998: 150 and more $(\mathrm{N}=49)$, from 40 to $149(\mathrm{~N}=67)$, and less than $40(\mathrm{~N}=56)$.

Nineteen Reporting Units were randomly sampled from each of these segments, and a 
facility was subsequently selected from each sampled Reporting Unit. Appendix A offers details about this process. Figure 1, which depicts the geographical distribution of the hospitals, health centers, and posts, reveals that the hospitals fell mainly in northern and central Peru, which are the

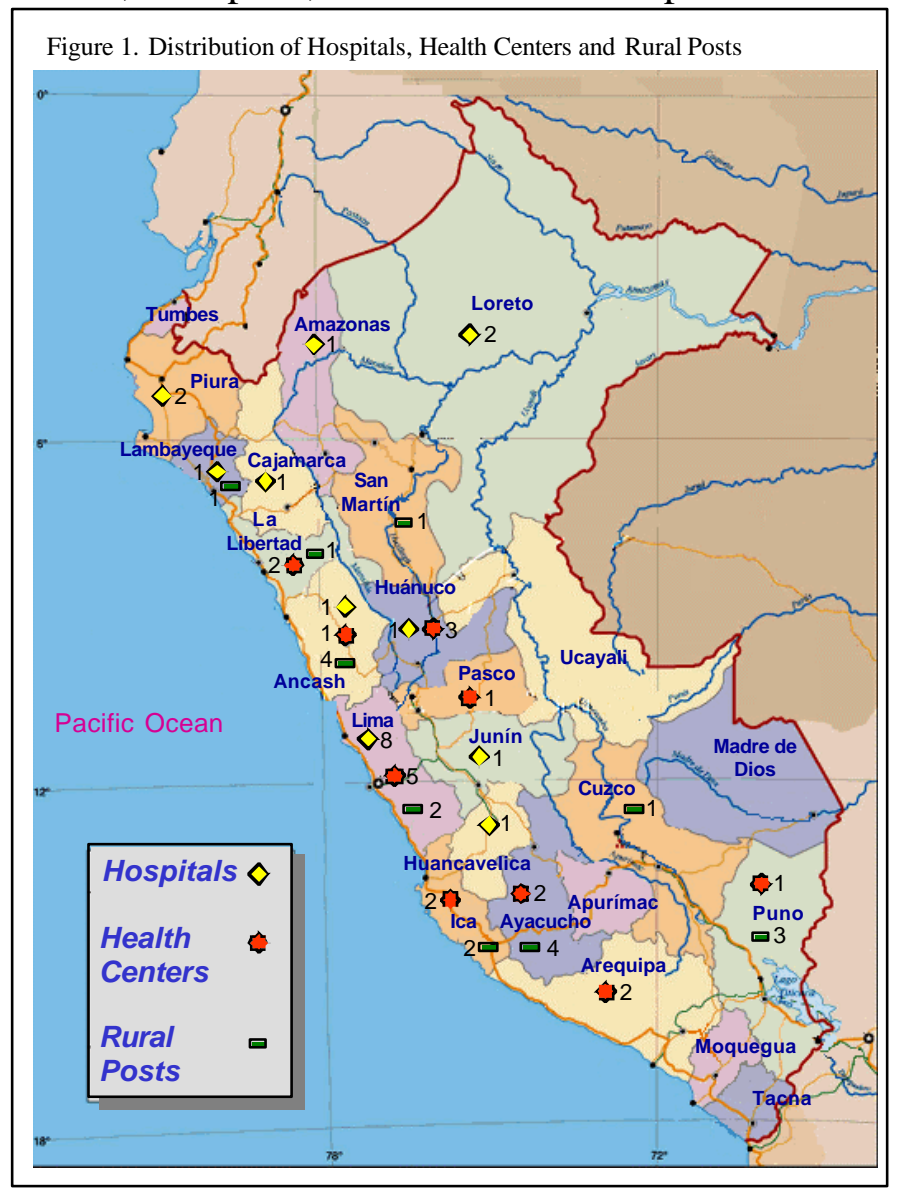

most populated areas of the nation. Health centers and posts were more evenly distributed. Only five departments (Tumbes, Ucayali, Madre de Dios, Moquegua, and Tacna) failed to be included in at least one of the samples.

\section{QUALITY ASSURANCE DECISION RULES}

A two-stage LQAS design was used to determine (1) whether an individual facility had reached a certain minimal threshold of quality of care (95 percent) and (2) whether a certain minimum proportion of facilities in the sample (80 percent) had satisfied that minimal threshold.

Six observations per facility were obtained; if five or more clients received adequate care, the facility was classified as performing adequately (we concluded that the facility had reached the 95 percent standard). This 6:1 decision rule correctly identifies 96.7 percent of the cases (specificity); the provider error, i.e., rejecting the lot when in fact 95 percent or more of the population of clients receive adequate care, is equal to $1-.967=.033$ or 3.3 percent.

Nineteen facilities per sample were obtained. If 13 or more facilities satisfied the individual 95 percent standard, the sample was classified as performing adequately (we concluded that the sample had reached the 80 percent standard). The probability of rejecting the lot when in fact 80 percent or more of the facilities offer adequate care is .068 or 6.8 percent; i.e., specificity under the 19:6 decision rule is 93.2 percent.

The sensitivity of these decision rules to Type II ("consumer") errors, as well as the difference between Inadequate and Very Inadequate performance and other aspects of the LQAS method implemented in the study, are described in Appendix B.

\section{SERVICE TEST}

Two Service Tests using trained simulated clients were designed to assess quality of care at hospitals and health centers. 
Nature of Instrument. This type of instrument, used before in Peru, Ecuador, and Honduras, avoids the judgmental problems and attendant low reliability associated with the use of ratings applied by simulated clients to wide behavioral areas (e.g., "Did the provider give you a choice of methods": 5 = Full, 4 = Wide, 3 = Moderate, 2 = Narrow, 1 = None; León et al., 1994a , 1994b). The Service Test consists of a) a client profile; b) a system to recruit and train simulated clients to seek services and enact this profile in interaction with a provider; and c) a checklist that includes a number of provider behavior items requiring Yes-No responses. Since the client needs are known, the checklist can focus on very specific provider behaviors (e.g., "Did the provider tell you what to do if you forget to take one pill?", "Did the provider perform a pelvic exam on you?").

Form A (Hospitals). Each of the 19 hospitals in Sample I was visited in different days by six simulated clients older than 30 who enacted a single profile. A total of 30 simulated clients participated at a rate of 4.22 hospitals visited per simulated client. They had been trained to seek services volunteering as little information about their intentions as possible and to wait until providers asked questions. (The recruitment, training, and supervision of simulated clients are described in Appendix C.) At the reception desk, the simulated client said, "I want family planning counseling." She gave her true name and age for the clinic history but a false local address. All the simulated clients actually had children and were using contraception. If asked about how many children they had, they would respond "Three," regardless of the actual number. If asked about the youngest one's age, they would give his/her actual age. When asked about contraceptive use, the simulated client mentioned the actual method she was using. She stated that she felt uncomfortable using it and wished to change to a more practical method, i.e., one that was free of daily requirements and/or side effects. The client profile indicated that she did not have the financial means to sustain a large family and that the husband agreed on a definitive solution, i.e., tubal ligation. If the provider asked about pregnancy status, she said she was using the protection of a temporary method; this included two women who used IUDs. As for her menses, the simulated client stated her true status at the moment. The simulated client accepted a pelvic exam if the provider so required. On average, each simulated client received a total of two pelvic exams. She was instructed to return to the facility as many times as needed and to enact the profile of a healthy woman without reproductive risk conditions and with no contraindications to voluntary surgical contraception. According to her profile, she had had her last Papanicolaou test about six months previously. If the consultation progressed to the point where the provider invited the simulated client to prepare for the operation, she would say that first she wanted to talk to her husband again, thank the provider, and leave. She filled out the checklist as soon as she left the premises.

Form B (Health Centers). Each of the 19 health centers of Sample II was visited in different days by six younger simulated clients who enacted a single profile. (See Appendix $\mathrm{C}$ about their recruitment, training, and supervision.) All of them did actually have one child. To inquiries about the child's age, they said, "One year old" or "One and a half years old" regardless of his/her actual age. A total of 27 simulated clients performed the visits at a rate of 3.8 health centers per simulated client. When asked about the use of contraception, the simulated clients said that they were using the rhythm method but that they did not feel secure because it had not stopped them from becoming pregnant and wanted a more effective method. Their client profile indicated that they lacked experience with other methods and should reject the pill and the IUD on various grounds. They rejected condoms saying their partner did not like to use them. They chose Depot Medroxy- 
progesterone Acetate (DMPA, or Depo-Provera) on practical grounds. When the provider asked about her menses, the simulated client said she was in her fourth day of menstruation. This answer was devised to indicate to the provider that she was not pregnant and to discourage a pelvic exam. Nevertheless, the simulated client accepted the pelvic exam if the provider required it. The simulated client was carefully trained to enact the profile of a healthy woman with no contraindications to the use of DMPA. According to her profile, she had had her last Papanicolaou test about six months previously. If the consultation progressed to the point that the provider was ready to administer the injection, the simulated client would say that she wanted to consult with her husband first, thank the provider and leave.

Provider Debriefing. After all the applications of the Service Test were completed $(\mathrm{N}=228)$, the simulated clients returned to the facilities to debrief the providers and offer individual feedback. (See Appendix C about this process.) In most instances, the providers volunteered justifications of the deficits observed in the simulated provider-client interactions which helped the evaluators to further understand the nature of the delivery problems.

\section{E. EXIT AND HOME INTERVIEWS}

Three types of interviews were implemented, one per sample: household follow-up of patients sterilized at hospitals, exit interview of family planning users coming out of consultations at health centers, and household follow-up of family planning users of rural health posts. Appendix D offers a description of interviewer training and supervision.

\section{Follow-Up of Sterilized Patients}

The MOH's National Family Planning Directorate facilitated contacts with regional authorities and hospital directors to obtain access to lists of users of VSC services at the 19 hospitals of Sample I. The 18 most recent cases were selected at each hospital, i.e., three times as many as needed. The addresses, however, were more unreliable than expected $(\mathrm{N}=44)$ and in several instances it was necessary to return to the list of VSC users at the hospital to collect more names and addresses. There were also persons who could not be found either because they were traveling or had moved. The total number of rejections of the interview was five.

The questionnaire designed for the home follow-up of patients sterilized at hospitals took into account the possibility that the client received a postpartum sterilization without her prior knowledge and/or consent. The main section of the instrument focused on the client's retrospective account of the decision processes leading to the surgical intervention and tapped her/his memories of the client-provider interaction. Most of the items had counterparts in the Service Test Form A checklist used at hospitals. However, the final section, concerned with the surgical and post-surgical phases of sterilization, was unique.

\section{Exit Interviews}

The MOH's National Family Planning Directorate wrote official letters to regional health directors and to directors of the health centers describing the research aims and introducing the research team. This allowed the interviewers to perform the task with full acceptance on the part of health center authorities. The interviewer stationed herself close to the consulting room to be able to 
identify family planning clients. Then she followed the client until the latter left the facility and only then approached her or him. Interviews were conducted outside facilities to permit the client to express freely about the process of consultation. Interviews were conducted in the order of arrival of the clients until six were completed, regardless of the type of client, new or continuer. ${ }^{1}$

Whereas the Service Test applied to consultations by new clients of the health center and exclusively focused on the client-provider interaction process, the exit interview encompassed more continuers than new clients and focused more on quality of care outcomes (e.g., client knowledge) than process. The questionnaire's first section contained items about the process of consultation taken from the Client Exit Interview Guidelines designed by Tulane University's MEASURE Evaluation Project and USAID's Monitoring and Evaluation Subcommittee of the Maximizing Access and Quality Committee (Bertrand, 1998). The second part was specially tailored to assess client knowledge concerning both family planning in general and about the specific method chosen.

\section{Follow-Up of Users of Rural Health Posts}

The MOH's National Family Planning Directorate facilitated contacts with regional authorities to obtain access to relevant information. At each Reporting Unit, data were obtained concerning user population of each individual facility. This permitted the researchers to randomly sample, weighted for size, one rural health post per Reporting Unit. Then, at each chosen health post, the 18 most recently engaged new clients were chosen from the list of clients registered as new family planning users during the first semester of 1999 and, if needed, second semester of 1998. Family Planning Coordinators helped in this process. Addresses were also obtained, and the selected clients were visited at their home. A few addresses were unreliable and in a large number of cases the person could not be found either because she or he was traveling or had moved $(\mathrm{N}=40)$. There were only three rejections of the interview. The questionnaire used was similar to the exit interview questionnaire. 


\section{RESULTS}

The results of the study are presented in tables arranged per substantive area. In each table, the first column either contains an "A", for Adequate, indicating that the item met the LQAS standard for the sample of facilities (80 percent), or is blank, showing a Very Inadequate classification. (See Appendix B for an explanation of the Very Inadequate classification.) These classifications are associated with the specificity and sensitivity levels specified in Appendix B.

The third and fourth columns of the tables offer the observed percentage over the 114 cases (six cases per each of 19 facilities) and the length of the respective .95 confidence interval, rounded to the nearest integers. These post facto point estimations were not considered in the sampling process and most of the resulting confidence intervals are wider than the usual $+/-5$ percentage points. Nevertheless, they are expected to be of practical use since they do discriminate between performance levels, though not as precisely as if a larger number of cases had been collected. The statistical inferences are legitimate; random processes took place in sampling.

\section{A. HOSPITALS}

The Service Test was implemented in the 19 hospitals of Sample I in June and July of 1999. Most of the providers servicing simulated clients in the first visit were nurse-obstetricians who provided the counseling and then referred them to a physician; nonprofessional health workers were rare. Two percent of the 114 cases made a total of four visits to the targeted hospitals, 25 percent made three visits, 39 percent made two visits, and 33 percent made only one visit. The first visit lasted 10 minutes or less in 17 percent of cases, between 11 and 20 minutes in 49 percent of cases, between 21 and 30 minutes in 26 percent of cases, and more than 30 minutes in 7 percent of cases.

The follow-up interviews of patients that were completed for each of the 19 hospitals of Sample I pertained to VSC procedures that had taken place between December 1998 and June 1999. Only three of the 114 interviewees were men. Thirty-two percent of the clients were between 21 and 30 years-old, 34 percent were between 31 and 34, and 33 percent were older than 35 . Only six percent said they could not read and write fluently. All had two or more living children. Only 15 percent had two children; 53 percent had three or four and 31 percent had between five and eight children. Seventy-five percent of the tubal ligations were performed in the postpartum period. At least one-fourth of the postpartum sterilizations were performed in the context of a cesarean section.

\section{Interpersonal Aspects}

The Service Test findings in this area, shown on Table 2, are generally positive. Only in a few hospitals clients were shown a video and the provider in these cases did not counsel the clients individually. Privacy was considered violated when, in any of the simulated client's visits to the hospital, the counseling was performed in the presence of other persons besides the counselor (except in the few cases that reached the operating room). ${ }^{2}$ The Very Inadequate privacy classifications may be Type I errors of the LQAS system - since the lower limits of the confidence intervals are greater than 50 percent. (See "Interindividual variation within facilities", Appendix E, for an explanation of a related issue.) Feelings pertaining to provider's concern for the client's well being are not equally positive. In their debriefing, the simulated clients said they felt a lack of 
concern if the provider, for example, failed to perform a pelvic exam, or ask about the partner.

Table 2. Interpersonal Behavior: Results of Service Test in Hospitals

\begin{tabular}{clcc}
\hline LOAS & Item & $\underline{\mathbf{\%}}$ & $\underline{\mathbf{+}-}$ \\
A & Counseling was personal & 93 & 5 \\
A & Client was received amiably & 100 & 0 \\
A & Client was treated respectfully & 98 & 2 \\
& There was visual privacy & 79 & 7 \\
& There was auditive privacy & 71 & 8 \\
& Client felt provider was concerned with her well being & 46 & 9 \\
\hline
\end{tabular}

Table 3 offers findings from the patient follow-up interviews. Consistent with Service Test observations, real clients reported that the providers had treated them courteously. The privacy afforded, however, was more limited; the punctual discrepancy with respect to the Service Test data may owe to the fact that real clients probably had more visits and stayed longer at hospitals, thus being exposed to increased opportunities for violation of privacy. Nevertheless, the general agreement of Service Test and follow-up data is remarkable.

Table 3. Interpersonal Behavior: Results of Sterilization Follow-Up

\begin{tabular}{cllc}
\hline LOAS & Item & $\underline{\mathbf{\%}}$ & $\underline{+/-}$ \\
A & Counseling: Client was received amiably & 89 & 6 \\
A & Counseling: Client was treated respectfully & 89 & 6 \\
A & Operating room: Client was received amiably & 96 & 4 \\
A & Operating room: Client was treated respectfully & 96 & 4 \\
& There was visual privacy & 44 & 9 \\
& There was auditory privacy & 43 & 9 \\
\hline
\end{tabular}

\section{General Information about Client}

According to the Service Test (see Table 4), providers asked most of the appropriate questions but few addressed the clients' reproductive intentions. Provider comments in the 
debriefing suggest that in several cases the simulated client, responding to provider questions in the consultation, may have revealed rather early her selection of tubal ligation, thus making it plain that she did not want to have any more children. As for the follow-up interviews with sterilized patients, only one of the items shown in Table 4 was included in the questionnaire: whether the provider asked the client if she wanted to have more children. This item was responded positively by 75 percent of the interviewees (.95 confidence interval: 67-83). The fact that real clients reported this provider behavior significantly more frequently than simulated clients may have owed to the fact that a majority of the real clients received the family planning counseling during antenatal consultations, i.e., in a context that lends itself more easily to reproductive intention issues and usually generates a greater number of contacts with providers than the family planning consultation. Nevertheless, this item did not achieve the LQAS standard.

Table 4. General Information about Client: Results of Service Test in Hospitals

\begin{tabular}{clccc}
\hline$\underline{\text { LQAS }}$ & $\underline{\text { Item }}$ & $\underline{\%}$ & $\underline{\mathbf{+}-}$ \\
A & Client was asked about her age & 98 & 2 \\
A & Client was asked how many children she had & 96 & 4 \\
& Client was asked if she wanted to have more children & 38 & 9 \\
A & Client was asked about her contraceptive use & 99 & 1 \\
\hline
\end{tabular}

Table 5. Method Choice: Results of Service Test in Hospitals

\begin{tabular}{clcc}
\hline LOAS & Item & $\underline{\mathbf{\%}}$ & $\underline{\mathbf{+}-\mathbf{-}}$ \\
$\mathrm{A}$ & Provider did not choose method & 94 & 4 \\
$\mathrm{~A}$ & Asked client which method she wanted to use & 87 & 6 \\
$\mathrm{~A}$ & Talked about other methods first; only then mentioned tubal ligation & 85 & 7 \\
& Talked about the pill & 75 & 8 \\
& Talked about DMPA & 71 & 8 \\
& Talked about the IUD & 73 & 8 \\
& Talked about barrier methods & 63 & 9 \\
& Spontaneously talked about tubal ligation & 69 & 8 \\
\hline
\end{tabular}




\section{Method Choice}

Simulated clients were given a free choice of method, with very few exceptions (e.g., one provider told a user of the IUD that she must continue using it and refused to provide tubal ligation). According to the results presented in Table 5, the context for the clients' decisions was in the majority of cases one of a flow of information about reversible methods coming from the provider. However, the items about specific methods failed to come up to the LQAS standard. In the debriefing, providers argued that they did not have enough time to be really exhaustive. Additionally, the fact that the simulated client was an older woman and already a user of a modern contraceptive may have led them to assume that she knew enough about reversible methods and was already committed to VSC.

Most real clients remembered having received family planning counseling (see Table 6) and felt they had made the method choice on their own. Very few attributed the decision to the provider or to a joint choice by client and provider. The figures entailing reversible methods offered by the provider are similar to those of the Service Test. The apparent contradiction between third and last items of Table 6 is explained by the fact that a majority of the clients, including both pregnant and non-pregnant women, visited the hospital with the mind already set on sterilization (Confidence interval for "Client visited the facility to seek VSC": 59-77) and they asked for the sterilization (5472). In only a minority of cases the provider suggested VSC during a consultation (17-33) or the idea emerged in a home visit (0-6). This explains why not all the providers asked about reproductive intentions or talked about alternative methods and why not all of the clients recognized having been given a method choice.

Table 6. Method Choice: Results of Sterilization Follow-Up

\begin{tabular}{clcc}
\hline LQAS & Item & $\underline{\mathbf{0}}$ & $\underline{\mathbf{+}-\boldsymbol{-}}$ \\
A & Client attended one or more counseling sessions & 89 & 6 \\
A & Client did not feel pressure from provider & 93 & 5 \\
A & Client's attribution of the decision to use VSC: Herself/himself & 92 & 5 \\
A & Client's attribution of the decision to use VSC: The provider & 2 & 3 \\
A & Client's attribution of the decision to use VSC: Jointly client and provider & 6 & 4 \\
& Provider offered injectable & 75 & 8 \\
& Provider offered pill & 74 & 8 \\
& Provider offered IUD & 75 & 8 \\
& Provider offered barrier methods & 68 & 9 \\
& Was given method choice & 62 & 9 \\
\hline
\end{tabular}


The interview was terminated in three cases (not included among the 114 cases considered in Table 6) because the pattern of responses detected by the questionnaire format led to the conclusion that the client might have undergone a sterilization she was not aware of. Re-interviews of these cases and further inquiries in the respective hospitals dispelled doubts with respect to two of them and we concluded that there was no violation of personal choice in these cases. In the third case, however, given the complexity of the case, we could not fully determine if the informed consent norm was followed. Appendix F describes the three cases, as well as a death registered in the reinterview period.

\section{Information Given to the Client}

Providers told simulated clients that the essential consequence of sterilization was that they would not be able to have any more children (see Table 7). This compensates in part for their failure to specifically ask the client about her reproductive intentions. They also informed the client about such basic aspects of the procedure as having to return for further counseling and/or exams and that sterilization services were free of charge. On the other hand, their information-giving behavior pertaining to possible method failure and complications was Very Inadequate. Information about action mechanisms and anesthesia were frequently observed, though did not reach LQAS standards. In the debriefing, providers attributed the observed failures to the lack of time and IEC materials. The first visit lasted more than 20 minutes only in 34 percent of the cases.

Table 7. Information given to the Client: Results of Service Test in Hospitals

\begin{tabular}{|c|c|c|c|}
\hline$\underline{\text { LQAS }}$ & $\underline{\text { Item }}$ & $\underline{\%}$ & $+1-$ \\
\hline \multirow[t]{3}{*}{ A } & Provider told client that she would not be able to have more children & 84 & 7 \\
\hline & That the union of spermatozoid and ovum is prevented & 82 & 7 \\
\hline & That she would be under anesthetic & 78 & 8 \\
\hline \multirow[t]{3}{*}{ A } & That client would have to return for further counseling or exams & 90 & 6 \\
\hline & That there was a certain (minimal) risk of method failure & 46 & 9 \\
\hline & That there was a risk of complications & 44 & 9 \\
\hline \multirow[t]{2}{*}{ A } & That the operation was free & 94 & 4 \\
\hline & Gave client a booklet about tubal ligation & 26 & 8 \\
\hline
\end{tabular}

Providers also told real clients that the essential consequence of sterilization was that they would not be able to have any more children (see Table 8). Nevertheless, this was not universal, and two clients said in the home interviews that they underwent the surgical procedure unaware of such a consequence. Their responses in the interview, nonetheless, did not indicate sterilization regret. Providers also informed the client that sterilization services were free of charge. On the other hand, 
Table 8. Information given to the Client: Results of Sterilization Follow-Up

\begin{tabular}{|c|c|c|c|}
\hline$\underline{\text { LQAS }}$ & $\underline{\text { Item }}$ & $\underline{\%}$ & \pm \\
\hline A & Provider told client that she would not be able to have more children & 89 & 6 \\
\hline \multirow[t]{5}{*}{ A } & When client was operated on she knew about this consequence of VSC & 98 & 2 \\
\hline & Provider told client that she would be under anesthetic & 75 & 8 \\
\hline & That there was a (minimal) risk of method failure & 29 & 8 \\
\hline & That there was a risk of complications & 25 & 8 \\
\hline & That she could change her mind & 45 & 9 \\
\hline \multirow[t]{3}{*}{ A } & That the sterilization was free & 93 & 5 \\
\hline & Provider asked client whether she had understood & 66 & 9 \\
\hline & Provider gave client a booklet concerning VSC & 36 & 9 \\
\hline
\end{tabular}

their information-giving behavior pertaining to possible method failure and complications and the client's right to change her mind in the following days, as well as handing in IEC materials, was Very Inadequate. Information given about the sse of anesthesia was frequently observed, though did not reach the LQAS standard.

\section{Screening for Contraindications}

Generally, a nurse-obstetrician provided the counseling to the simulated client and then a physician performed the clinical examination. Adequate screening for contraindications of the candidate for sterilization was limited to one item: providers made sure that the client was not pregnant (Table 9). Many asked about Papanicolaou results but this item failed to reach the LQAS standard. Debriefed providers placed the blame on the limited time alloted to each consultation, memory problems, and a norm stating that only certain cases should be tested for cardiological risk.

When the simulated clients were given an appointment for further exams and the surgical procedure both in a single visit, they did not return to the hospital. Alternatively, they abandoned the consultation when they were asked to undress to be shaved for a pelvic examination and subsequent surgical procedure. Because of these reasons, they may have missed the opportunity to receive an exhaustive clinical examination. Yet, against this interpretation is the fact that the Lima hospitals performed pelvic examinations in 81 percent of the cases, while provincial hospitals did so in only 33 percent of the cases (chi-square $=28.8, p<.001$, two-tailed) despite that the number of visits to hospitals were similar in Lima (Mean: 1.81) and the provinces (Mean: 2.06). ${ }^{3}$ Hence, whether or not the pelvic exam is reported by the simulated client seems to depend more on the quality of care offered by the facility than on the number of visits completed by the simulated client.

Only 56 percent of the real clients remembered having received a pelvic exam, a finding that 
Table 9. Screening for Contraindications: Results of Service Test in Hospitals

\begin{tabular}{|c|c|c|c|}
\hline$\underline{\text { LOAS }}$ & $\underline{\text { Item }}$ & $\underline{\%}$ & \pm \\
\hline \multirow[t]{10}{*}{ A } & Provider asked client about possible pregnancy or date of last menstruation & 93 & 5 \\
\hline & Whether she was sure she did not wish to have any more children & 51 & 9 \\
\hline & $\begin{array}{l}\text { Whether she had symptoms of any pelvic inflammatory disease or had undergone } \\
\text { a pelvic operation }\end{array}$ & 60 & 9 \\
\hline & Whether she had come with her partner or if he knew about this visit & 26 & 8 \\
\hline & Whether she had had a Papanicolaou test recently & 77 & 8 \\
\hline & Performed a pelvic exam on client & 53 & 9 \\
\hline & Measured her blood pressure & 51 & 9 \\
\hline & Took her temperature & 11 & 6 \\
\hline & Requested blood tests & 52 & 9 \\
\hline & Gave her an appointment to evaluate her cardiological risk & 25 & 8 \\
\hline
\end{tabular}

is consistent with Service Test results. The questionnaire used in the follow-up of sterilized patients did not include other items on contraindication checks by the provider. ${ }^{4}$

\section{Informed Consent and Reflection Period}

The MOH's guidelines require two counseling sessions involving the VSC client, one about general family planning and the other about VSC. We already know from Table 5 that the provider talked about reversible methods and from Table 7 that he/she addressed specific sterilization items. Table 10 refers to other provider behaviors in the area of informed consent. All are classified as Very Inadequate, although a majority of the providers asked the client to sign the VSC Request Form. In some instances, providers made clients sign the VSC Request form without prior reading. In others, they informed the client about the 72-hour reflection period as they offered to exonerate her of this requirement in the absence of reproductive risk conditions. The negative significance of these provider behaviors is attenuated by the fact that the "client" had not begun to consider sterilization during the consultation but was a person who had thought hard about this option before coming for the appointment. Nevertheless, this is an area with considerable room for improvement. In the debriefing some providers complained about the lack of VSC Request forms.

The requirement of two counseling sessions was not met according to the interviewed patients (see Table 11), though they may have confused sessions with visits. Of greater concern is the finding that a Very Inadequate number of providers read aloud or made the client read the VSC Request form. Whereas we cannot entirely discard client memory lapses as a confounder here, the Service Test findings in this area strengthen the hypothesis that providers do not comply with the norm. On the other hand, an Adequate number of clients remembered having signed some sort of 
Table 10. Informed Consent and Reflection Period: Results of Service Test in Hospitals

\begin{tabular}{|c|c|c|c|}
\hline \multirow[t]{8}{*}{$\underline{\text { LOAS }}$} & $\underline{\text { Item }}$ & $\underline{\%}$ & \pm \\
\hline & Provider told client that she could decide at any moment not to have the operation ${ }^{5}$ & 30 & 8 \\
\hline & Read out or asked client to read VSC Request Form & 60 & 9 \\
\hline & Asked client to sign the VSC Request Form & 75 & 8 \\
\hline & Gave client a copy of completed VSC Request Form & 22 & 8 \\
\hline & Told client about the 72-hour reflection period & 30 & 8 \\
\hline & Told client that she could waive the reflection period & 10 & 6 \\
\hline & Asked client to sign reflection period waiver & 30 & 8 \\
\hline
\end{tabular}

document. Whereas the signature of the Form was reported by 53 percent of the clients, a significant number of interviewees said they did not remember the content of what they signed (38 percent). A Very Inadequate number of providers mentioned the 72-hour reflection period, ${ }^{6}$ which appears to be justified considering the fact that two-thirds of the clients were undergoing antenatal counseling. Yet, only a minority of clients waited 72 or more hours after the last counseling before returning to the hospital for the surgical procedure, which suggests that in a number of cases the family planning counseling was offered the same day of the birth. In fact, in 32 percent of the cases (postpartum plus interval) the surgical procedure took place the same day of the last counseling.

Table 11. Informed Consent and Reflection Period: Results of Sterilization Follow-Up

\begin{tabular}{|c|c|c|c|}
\hline$\underline{\text { LQAS }}$ & $\underline{\text { Item }}$ & $\underline{\%}$ & $\underline{+}+-$ \\
\hline \multirow{9}{*}{ A } & Client received two or more counseling sessions & 56 & 9 \\
\hline & Provider read out or asked client to read VSC Request Form & 57 & 9 \\
\hline & Client signed the VSC Request form & 53 & 9 \\
\hline & Client signed any document(s) & 90 & 6 \\
\hline & Signed one document & 35 & 9 \\
\hline & Signed two documents & 23 & 8 \\
\hline & Signed three documents & 23 & 8 \\
\hline & Provider told client about the 72-hour reflection period & 41 & 9 \\
\hline & At least 72 hours elapsed between last counseling and surgical procedure & 40 & 9 \\
\hline
\end{tabular}




\section{Closing the Consultation/Discharging the Patient}

Results of the Service Test are shown in Table 12. The fact that providers were fully understood must be viewed in light of the fact that the simulated clients were above average in education. Nonetheless, providers should have verified client understanding. Finally, some simulated clients found it very hard to escape from the situation. Providers had invested time and resources and now the client backed down from her decision to proceed with the surgery. In some instances, providers showed their displeasure. In one case, the simulated client resolved the situation by asking for and receiving a Depo-Provera njection instead of the sterilization. ${ }^{7}$ In the debriefing, providers of one small provincial hospital said they suspected some cases were simulated clients because of their curiously similar response pattern (e.g., saying that they had to consult again with their husbands and then failing to return to the hospital).

Table 12. Closing the Consultation: Results of Service Test in Hospitals

\begin{tabular}{clcc} 
LOAS & Item & $\underline{\%}$ & $\underline{+/-}$ \\
A & Client understood everything provider said & 95 & 4 \\
& Provider asked client whether she had understood & 35 & 9 \\
& Verified client understanding & 6 & 4 \\
& Told client where to go in case of problem or doubt & 24 & 8 \\
\hline
\end{tabular}

According to the follow-up interviews, only 28 percent of the clients stayed less than 24 hours at the hospital after the surgical procedure. This can be explained by the fact that most interventions were in the postpartum period. An Adequate number of clients were given an appoint-

Table 13. Discharging the Client: Results of Sterilization Follow-Up

\begin{tabular}{|c|c|c|c|}
\hline$\underline{\text { LQAS }}$ & $\underline{\text { Item }}$ & $\underline{\%}$ & \pm \\
\hline \multirow[t]{7}{*}{ A } & Client was given an appointment for follow-up & 88 & 6 \\
\hline & Provider specified symptoms that should accelerate return to the hospital & 62 & 8 \\
\hline & Said she must return if the wound ached or inflammation was observed & 43 & 9 \\
\hline & If she had fever & 23 & 7 \\
\hline & If she had a stomach ache & 22 & 6 \\
\hline & If she felt dizzy & 9 & 5 \\
\hline & If she observed bleeding & 9 & 5 \\
\hline
\end{tabular}


ment for a follow-up visit (see Table 13). However, only 62 percent of the clients were alerted, generally after the surgical procedure, about the medical conditions under which they should accelerate their return to the hospital. Table 13 also offers data concerning the specific conditions defined by providers.

\section{Client Payments}

The hospitals behaved according to the LQAS standard in this area (see Table 14).

Table 14. Client Payments: Results of Service Test in Hospitals

\begin{tabular}{clcc}
\hline LQAS & Item & $\underline{\boldsymbol{\%}}$ & $\underline{\mathbf{+}-\mathbf{z}}$ \\
A & The opening of a clinic history was free of charge & 74 & 8 \\
A & The consultation was free of charge & 99 & 1 \\
A & The laboratory tests were free of charge & 86 & 6 \\
\hline
\end{tabular}

\section{Client Satisfaction}

Real clients were substantially satisfied with the services received; 86 per cent said they would recommend the service to a close friend. On the other hand, the rate of sterilization regret was noteworthy (17 percent; confidence interval: 10-24). The presence of regret, however, does not imply that decisions were not informed or voluntary.

\section{Interindividual Variation Within Facilities}

The significance of the variation of provider behavior between and within facilities is analyzed in Appendix E.

\section{B. HEALTH CENTERS}

Six visits by simulated clients and six client exit interviews were completed at each of the 19 health centers of Sample II in July and August of 1999. More than 60 percent of the 114 Service Test consultations lasted less than 15 minutes. Thirty percent lasted 16-30 minutes. The remainder lasted between 31 and 45 minutes.

As for the real clients, only one of the 114 interviewees was a man. Thirty-six percent of the clients were younger than 24 years-old, 38 percent had between 25 and 30 years, and 26 percent were older than 30 . Only 83 percent said they were ble to read and write Spanish fluently. It took less than 15 minutes for 56 percent of them to reach the health center, while 29 percent invested between 16 and 40 minutes and 15 percent more than 40 minutes. Eighty-three percent of the clients were already using contraception, mainly the injectable (59 percent of them) and secondarily the pill (19 percent of them). Most of these were continuers who came to the health center for resupply; questions concerning method choice pertained to their distant memory and were not addressed. 


\section{Interpersonal Behavior}

Providers showed adequate interpersonal behaviors and privacy was attained to a larger extent than in hospitals (see Table 16). Results about concern shown by the provider were identical to those observed at hospitals. The exit interviews produced optimal results (see Table 17).

Table 16. Interpersonal Behavior: Results of Service Test in Health Centers

\begin{tabular}{clccc}
\hline$\underline{\text { LOAS }}$ & $\underline{\mathbf{I t e m}}$ & $\underline{\mathbf{\%}}$ & $\underline{\mathbf{+}-}$ \\
A & Counseling was individual & 100 & 0 \\
A & Client was treated with respect & 90 & 6 \\
A & There was visual privacy & 88 & 6 \\
A & There was auditive privacy & 82 & 7 \\
& Client felt the provider was concerned with her well being & 46 & 9 \\
\hline
\end{tabular}

Table 17. Interpersonal Behavior: Results of Client Exit Interviews

\begin{tabular}{clcc}
\hline$\underline{\text { LOAS }}$ & Item & $\underline{\mathbf{\%}}$ & $\underline{\mathbf{+}-\mathbf{z}}$ \\
A & There was visual privacy & 94 & 4 \\
A & There was auditive privacy & 92 & 5 \\
A & Client felt treated with respect by provider & 99 & 1 \\
A & Client felt treated with respect by other personnel & 99 & 1 \\
\hline
\end{tabular}

\section{General Information about Client}

Providers formulated most of the expected questions about the simulated client (see Table 18) but did not ask whether the client wanted more children. Since the client was using contraception, they correctly thought that she did not want a child immediately. On the other hand, providers, instead of asking the specific question, considered the client's age and current number of children and incorrectly assumed that she would want more children in the future. Neither did they inquire into the client's use of the rhythm method to ascertain whether she had been using it appropriately. They just accepted the client's idea that the natural family planning method was worthless.

According to the exit interviews, only 44 percent of the providers asked about client reproductive intentions, and even less inquired about other aspects of client life (see Table 19). Yet, most clients were continuers, and hence came with a clinic history. Therefore, in these cases the 
Table 18. General Information about Client: Results of Service Test in Health Centers

\begin{tabular}{clcc}
\hline$\underline{\text { LOAS }}$ & $\underline{\mathbf{I t e m}}$ & $\underline{\mathbf{\%}}$ & $\underline{\mathbf{+ /}}$ \\
A & Provider asked client's age & 96 & 4 \\
A & Provider asked about client's number of children & 96 & 4 \\
& Provider asked if client wanted more children & 7 & 5 \\
A & Provider asked about client's contraceptive use & 82 & 7 \\
& Provider asked how client was using the rhythm method & 12 & 6 \\
\hline
\end{tabular}

provider may have not needed to ask questions. The information was already available in the clinic history.

Table 19. General Information about Client: Results of Client Exit Interviews

\begin{tabular}{llcc}
\hline$\underline{\text { LQAS }}$ & $\underline{\text { Item }}$ & $\underline{\mathbf{\%}}$ & $\underline{\mathbf{+ l}}$ \\
& Provider asked about client's reproductive intentions & 44 & 9 \\
Asked or talked about sexually transmitted diseases & 22 & 8 \\
About the client's sexuality & 19 & 7 \\
About partner relations & 26 & 8 \\
\hline
\end{tabular}

\section{Method Choice}

This was the strongest service area (see Table 20). The provider offered the client a wide choice of methods including condoms, vaginal tablets, pills, DMPA, and IUD, and showed no bias or preference for any particular method. (Implants and vasectomy were not included in the checklist.) Essentially the client chose the method. Only on two issues was the providers' behavior substandard. First, the provider discarded the rhythm method as a valid option (owing to the fact that the client was dissatisfied with it) and made no attempt to tell her about its proper use. Second, the provider failed to offer sterilization to all clients, sometimes saying to the client that she was too young for sterilization or that she had not yet attained an ideal family size.

In the case of the real clients, 86 percent of the continuers received a method during the consultation, 60 percent of them the injectable, 24 percent the pill, 7 percent condoms, and 9 percent other methods. 
Table 20. Method Choice: Results of Service Test in Health Centers

\begin{tabular}{|c|c|c|c|}
\hline$\underline{\text { LQAS }}$ & $\underline{\text { Item }}$ & $\underline{\%}$ & $+1-$ \\
\hline & Provider talked about the rhythm method & 24 & 8 \\
\hline A & Provider talked about condoms & 82 & 7 \\
\hline A & Provider talked about vaginal tablets & 79 & 7 \\
\hline A & Provider talked about the pill & 95 & 4 \\
\hline A & Provider talked about Depo-Provera & 88 & 6 \\
\hline \multirow[t]{2}{*}{ A } & Provider talked about the IUD & 84 & 7 \\
\hline & Provider talked about tubal ligation & 26 & 8 \\
\hline A & Provider did not insist on the rhythm method & 99 & 1 \\
\hline A & Provider did not insist on condoms & 96 & 4 \\
\hline A & Provider did not insist on vaginal tablets & 97 & 3 \\
\hline A & Provider did not insist on pills & 88 & 6 \\
\hline A & Provider did not insist on Depo-Provera & 83 & 7 \\
\hline A & Provider did not insist on the IUD & 88 & 6 \\
\hline A & Provider did not insis t on tubal ligation & 100 & 0 \\
\hline A & Provider asked the client to make a choice of methods & 96 & 4 \\
\hline
\end{tabular}

\section{Action Mechanism and Usage Instructions}

Provider behavior pertaining to information given to the client about the action mechanisms of DMPA was Very Inadequate (see Table 21). In an earlier diagnostic study conducted in the province of Santa, Peru (León, 1997), providers said they omitted this type of explanation because they believed the client would not understand. Providers of the present evaluation did not volunteer this type of information in the debriefing. As for usage instructions, only the one referring to the administration of the injection every three months was Adequate. The instruction to initiate use of the method during menstruation was observed in 70 percent of cases and did not meet the LQAS standard. Providers attributed these failures to the lack of time or memory lapses.

\section{Instructions to Use Barrier Methods}

At the end of the consultation, the simulated client gave an excuse to avoid actually having the injection. In some instances, the provider discharged the client handing in a dose of DMPA; in others, he/she just recommended the client the application of the injection as soon as she was ready, or gave her an apointment to return to the facility. Given this scenario, the provider was expected to 
Table 21. Action Mechanism and Usage Instructions: Results of Service Test in Health Centers

\begin{tabular}{|c|c|c|c|}
\hline \multirow[t]{5}{*}{$\underline{\text { LQAS }}$} & $\underline{\text { Item }}$ & $\underline{\%}$ & $+1-$ \\
\hline & Provider told client that the injection would stop ovulation & 36 & 9 \\
\hline & That her cervical mucus would thicken & 10 & 6 \\
\hline & That the first injection is administered in the first five days of menstruation & 70 & 8 \\
\hline & That the injection is administered in the buttocks & 46 & 9 \\
\hline \multirow[t]{3}{*}{ A } & That the following doses are applied every 3 months & 93 & 5 \\
\hline & That the margin allowed is two weeks before or after the scheduled date & 4 & 4 \\
\hline & Provider gave client a leaflet with information & 27 & 8 \\
\hline
\end{tabular}

recommend the client to use barrier methods in the meantime and to give her the corresponding use instructions. Provider behaviors in this area were Very Inadequate (see Table 22), as few providers offered such advice. Most of the usage instructions for barrier methods reported in the table were offered earlier in the consultation, as the provider described the array of contraceptive methods.

Table 22. Instructions to Use Barrier Methods: Results of Service Test in Health Centers

\begin{tabular}{|c|c|c|c|}
\hline \multirow[t]{10}{*}{$\underline{\text { LQAS }}$} & $\underline{\text { Item }}$ & $\underline{\%}$ & \pm+- \\
\hline & Provider told client to use condoms or tablets in meantime & 18 & 7 \\
\hline & That coitus must be initiated with the condom on & 47 & 9 \\
\hline & That the condom must be removed while the penis still is erect & 20 & 7 \\
\hline & That each coitus requires a new condom & 38 & 9 \\
\hline & That the vaginal tablet must be inserted 15 minutes before coitus & 54 & 9 \\
\hline & That she must be prone when she inserts the tablet & 29 & 8 \\
\hline & That the tablet is effective for one hour & 18 & 7 \\
\hline & That a new coitus requires a new tablet & 25 & 8 \\
\hline & That she must avoid performing a vaginal douche during the next hours & 24 & 8 \\
\hline
\end{tabular}




\section{Screening for Contraindications}

The Peru MOH guidelines consider four contraindications to the use of DMPA: pregnancy, abnormal vaginal bleeding, breast cancer, and active liver disease. Table 23 refers to questions asked by the provider or advice given the simulated client about contraindications concerning the method chosen by the client (DMPA). The results were not as good as those observed in the method choice area. The provider only made efforts to discard pregnancy, which he/she promptly did since the simulated client responded to the question about menses saying she was in her fourth day of menstruation. (Other items in the checklist concerned with suspicion of pregnancy have been omitted in Table 23.) LQAS decision rules classified as Very Inadequate provider's screening for contraindications with respect to cervical cancer, breast cancer, and liver diseases. Providers thought that the client was too young to be at risk. Others said in the debriefing that they just forgot to consider all the contraindications or that the time limitations impeded them to be more exhaustive.

Table 23. Screening for Contraindications: Results of Service Test in Health Centers

\begin{tabular}{|c|c|c|c|}
\hline$\underline{\text { LQAS }}$ & $\underline{\text { Item }}$ & $\underline{\%}$ & $\pm /-$ \\
\hline \multirow[t]{8}{*}{ A } & Provider asked client about date of last menstruation & 97 & 3 \\
\hline & Provider asked/told client about non-menstrual vaginal bleeding & 3 & 3 \\
\hline & Provider asked client about date of last Papanicolaou exam & 25 & 8 \\
\hline & Provider performed or wanted to perform a pelvic exam & 3 & 3 \\
\hline & Provider asked/told client about family history of breast cancer & 5 & 4 \\
\hline & Provider performed/told client about a breast exam & 4 & 4 \\
\hline & Provider asked/told client about hard formations in the breast & 9 & 5 \\
\hline & Provider asked/told client about liver problems & 32 & 9 \\
\hline
\end{tabular}

The exit interviews showed a marginally better pattern, though still poor (Table 24). Yet, the fact that most clients were continuers and the relevant information probably was already part of the

Table 24. Screening for Contraindications: Results of Client Exit Interviews:

\begin{tabular}{llcc}
$\underline{\text { LOAS }}$ & $\underline{\text { Item }}$ & $\underline{\mathbf{\%}}$ & $\underline{+/-}$ \\
& Talked about Papanicolaou test & 52 & 9 \\
Talked about breast exam & 17 & 7 \\
Performed a pelvic examination & 24 & 8 \\
\hline
\end{tabular}


clinic history must be taken into account.

\section{Information About Side Effects}

The provider warned the simulated client about possible alterations of the menstrual pattern; specifically, that menstruation could stop altogether (see Table 25). On the other hand, the other four side effects did not reach the Adequate level. In a study in rural and semi-rural settings of Peru, providers said that they preferred not to inform clients about side effects to avoid scaring them off (León et al., 1994a). In the present evaluation, providers explained their failures referring to bck of time and memory lapses.

\section{Table 25. Information about Side Effects: Results of Service Test in Health Centers}

$\begin{array}{clcc}\text { LQAS } & \text { Item } & \underline{\mathbf{0}} & \underline{\mathbf{+}-} \\ \mathrm{A} & \text { Provider told client that menstruation might stop altogether } & 84 & 7 \\ & \text { That menstruation may be irregular or spotting may be observed } & 77 & 8 \\ & \text { That neither amenhorrea nor spotting is a symptom of illness } & 44 & 9 \\ & \text { That she might gain weight } & 37 & 9 \\ & \begin{array}{l}\text { That if she stops using DMPA it might take between } 6 \text { and } 12 \text { months before she } \\ \text { could conceive again }\end{array} & 14 & 6\end{array}$

\section{Closing the Consultation}

The simulated clients understood all the questions and instructions from the provider. Yet the provider did not verify whether the client had understood (see Table 26). Nor did the provider tell the client about warning signs or invite her to return to the health center whenever she had any doubt concerning the use of DMPA.

Table 26. Closing the Consultation: Results of Service Test in Health Centers

\begin{tabular}{clcc}
\hline$\underline{\text { LOAS }}$ & Item & $\underline{\%}$ & $\underline{+/-}$ \\
A & Client understood what the provider said & 91 & 6 \\
& Provider asked if she had understood & 23 & 8 \\
& Provider verified client's understanding & 3 & 3 \\
& Told client to return if she had abundant vaginal bleeding & 12 & 6 \\
& Told client to return if she had any doubt & 12 & 6 \\
\hline
\end{tabular}




\section{Client Payments}

Only 69 percent of cases did not have to pay for the consultation (see Table 27); yet the distribution of cases satisfied the LQAS standard, suggesting that this was a consistent normative behavior. Clients were not required to pay for the method, either.

Table 27. Client Payments: Results of Service Test in Health Centers

\begin{tabular}{clcc}
\hline LOAS & Item & $\underline{\mathbf{\%}}$ & $\underline{+/-}$ \\
A & Client did not have to pay for the consultation & 69 & 8 \\
A & Client did not have to pay for the method & 100 & 0 \\
\hline
\end{tabular}

\section{General Family Planning Knowledge}

In the exit interview each client was asked two questions about each of eight family planning methods, and the interviewers registered whether she had produced a correct answer spontaneously. If she failed to do so, the interviewer read the correct answer aloud and asked the client whether she agreed this was the correct answer. The "Yes" responses were registered as aided correct responses. Table 28 shows the corresponding percentages. A circle around a percentage indicates attainment of the LQAS standard. The respective confidence intervals ranged from $\%+/-1.83$ through $\%+/-9.18 .^{8}$

Spontaneous correct responses pertaining to the pill, injectable, and VSC are more prevalent than those about other methods. This can be understood in part as a result of (a) the fact that most of the informants were users of these hormonal methods and (b) method shifting from pill to injectable and vice versa prevails in the user population (Noble et al., 1998). The high level of correct responses pertaining to the essential consequences of sterilization may owe in part to the MOH's emphasis on this method in 1996-97 and the ensuing debate in the media. Three other responses, entailing the condon, the pill, and the injectable, met the LQAS standard when either spontaneous or aided responses were considered. Items entailing sexually transmitted diseases, vaginal tablet, and vasectomy show high raw percentages of occurrence of correct responses but do not reach the LQAS standard.

\section{Method Chosen for Further Inquiry}

One method was chosen for further inquiry in the exit interview: the method received in the consultation. If no method was received, the inquiry referred to the method the client was counseled on during the consultation. If neither method nor counseling were received, the inquiry focused on the method used by the client when she came to the consultation. Since most clients were continuers who came for resupply, the inquiry pertained to the method used in 66 percent of the cases. Only in 34 percent of the cases the inquiry pertained to a method that was new to the client. In either circumstance, it involved mainly the injectable (56 percent of the cases) and the pill (23 percent) and secondarily the condom ( 8 percent), IUD (6 percent), vaginal tablet and lactational amenorrhea (3 percent each), and VSC and rhythm (1 percent each). ${ }^{9}$ 
Table 28. General Family Planning Knowledge: Results of Client Exit Interviews

\begin{tabular}{|c|c|c|c|}
\hline$\underline{\text { Item }}$ & Spontaneous & $\underline{\text { Aided }}$ & Either \\
\hline Rhythm method requires abstinence or protected intercourse in some days & 54 & 20 & 74 \\
\hline Fertile interval starts at about $8^{\text {th }}$ day of the cycle and lasts 10 to 12 days & 26 & 5 & 32 \\
\hline Condom is placed on penis before starting intercourse & 68 & 13 & \\
\hline Condom protects against sexually transmitted diseases & 68 & 11 & 78 \\
\hline Vaginal tablet is inserted in vagina before intercourse & 60 & 14 & 74 \\
\hline Vaginal tablet is inserted about 15 minutes before intercourse* & 37 & 6 & 43 \\
\hline Pill is taken every day & 77 & 11 & \\
\hline There is a risk of pregnancy if pill is not taken every day & & 5 & \\
\hline The injectable is applied every 3 months & & 1 & \\
\hline Menstrual alterations are the main side effects of the injectable & 38 & 47 & \\
\hline The IUD is inserted into the uterus & 49 & 11 & 61 \\
\hline The IUD lasts 10 years $* *$ & 65 & 1 & 66 \\
\hline The sterilized woman will not have more children & 5 & 11 & $87)$ \\
\hline There is some risk of complications in tubal ligation & 35 & 15 & 50 \\
\hline The vasectomized man will not have more children & 64 & 14 & 78 \\
\hline 3 months or 20 ejaculations are required for effective vasectomy & 3 & 11 & 14 \\
\hline
\end{tabular}

Included in the section of the questionnaire dealing with the method chosen for further inquiry were questions about general characteristics of the method (e.g., condom protects against sexually transmitted diseases), usage instructions (e.g., vaginal tablet is inserted into the vagina 15 minutes before intercourse), and practical requirements of the client (e.g., lactation must be exclusive in lactational amenorrhea). They ranged from two items in the case of lactational amenorrhea to eight in the case of tubal ligation. Table 29 offers the relevant results in terms of number of items known. If an item (a) was included among the earlier questions pertaining to general family planning knowledge, (b) generated an aided correct response in that section of the questionnaire, (c) was repeated as a question about the method chosen, and (d) generated a spontaneous correct response here, it was classified in Table 29 as an aided correct response. Clients offered at least two correct responses about the method chosen for further inquiry, one spontaneous and the other aided. When either spontaneous or aided correct responses are considered, the conclusion is that clients know three general items about the method chosen for further inquiry. 
Table 29. General Knowledge about Method Chosen: Results of Client Exit Interviews

One or more
Two or more
$\begin{aligned} & \text { Three or more } \\ & \text { Four or more }\end{aligned}$

In the section of the exit interview questionnaire entailing knowledge about contraindications, these ranged from one item in the case of vaginal tablets to 10 in the case of pills. To make it possible the application of LQAS decision rules, users of methods without contraindications (e.g., rhythm, condom) were counted as knowing the contraindications of its method. As shown in Table 30, client knowledge in this area was very limited.

Table 30. Knowledge about Contraindications of Method Chosen: Results of Client Exit Interviews

\begin{tabular}{lccccc} 
Number of Items & Spontaneous & Aided & & Either \\
One or more & 34 & 73 & 52 & 65 \\
Two or more & 6 & 36 & 43 \\
Three or more & 2 & 17 & 22 \\
Four or more & 1 & \\
\hline
\end{tabular}

Table 31. Knowledge about Side Effects of Method Chosen: Results of Client Exit Interviews

\begin{tabular}{lcccc} 
Number of Items & Spontaneous & Aided & Either \\
One or more & 69 & 71 & 47 \\
Two or more & 42 & 14 & 63 \\
Three or more & 42 & 4 & 41 \\
Four or more & 4 & 45 \\
\hline
\end{tabular}

The side effects considered in the knowledge section of the exit interview questionnaire ranged from one of lactational amenorrhea to four of the injectable. To make it possible the 
application of LQAS decision rules, users of methods without side effects (e.g., rhythm, condom) were counted as knowing the side effects of its method. Clients demonstrated that they only knew one side effect of its method (see Table 31).

In the exit interview questionnaire, knowledge items concerning follow-up ranged from one in the case of tubal ligation to four in the case of other methods (e.g., pill, injectable). Clients showed more knowledge concerning when to return to the facility than about method side effects or contraindications (see Table 32).

Table 32. Knowledge about Follow-Up: Results of Client Exit Interviews

\begin{tabular}{l}
$\begin{array}{l}\text { Number of Items } \\
\text { One or more } \\
\text { Two or more } \\
\text { Three or more } \\
\text { Four or more }\end{array}$ \\
\hline
\end{tabular}

Generally, user knowledge about the method chosen was incomplete, and this had a subjective correlate: only 34 percent of the clients felt hat they had all the information needed to use their method. The limited duration of most consultations may help explain the observed shortcomings. These conclusions, however, have to be qualified. The client's judgment regarding the completeness of her or his information was expressed after she or he was subjected to the knowledge questions and may have been influenced by this sequence.

\section{HEALTH POSTS}

Six follow-up interviews were completed for each of the 19 health posts of Sample III in July-August of 1999 . Only five of the 114 interviewees were men. Thirty-five percent of the clients were 24 years-old or younger, 33 percent were between 25 and 30 years old, and 32 percent were older than 30 .

Only two percent had been enrolled as new clients in late 1998. Forty percent enrolled between January and March 1999, 43 percent between April and June, and 15 percent as recently as July or August. Only 71 percent said they could read and write Spanish fluently, and only 2 percent did not have children. Sixty four percent had between one and three children. Thirty three percent had between four and 10 children. Questions about time taken to reach the health post were not formulated because the rural population is not used to calculate time in terms of minutes and hours.

At the moment of the interview, 51 percent of the clients were using the injectable, 13 percent the pill, 18 percent other modern methods, 6 percent traditional methods, and 12 percent were discontinuers of family planning. 


\section{Interpersonal Behavior and Reproductive Intentions}

There was visual privacy and the client felt she/he was well treated (see Table 33). On the other hand, auditive privacy and provider inquiries concerning client reproductive intentions failed to reach the LQAS standard despite the existence of high percentages of occurrence of the expected provider behaviors.

Table 33. Interpersonal Behavior and Reproductive Intentions: Results of Rural Follow-Up

\begin{tabular}{|c|c|c|c|}
\hline$\underline{\text { LQAS }}$ & $\underline{\text { Item }}$ & $\underline{\%}$ & \pm \\
\hline \multirow[t]{2}{*}{ A } & There was visual privacy & 86 & 6 \\
\hline & There was auditive privacy & 74 & 8 \\
\hline A & Client was treated with respect by provider & 94 & 4 \\
\hline \multirow[t]{3}{*}{ A } & Client was treated with respect by others & 89 & 6 \\
\hline & Provider asked client whether he/she wanted to have children ever & 79 & 7 \\
\hline & Provider asked client when she wanted to have children & 48 & 9 \\
\hline
\end{tabular}

\section{Informed Choice}

The decision to use contraception was made by the client in an overwhelming majority of cases (see Table 34) and was justified by diverse reasons - family size, economic conditions, health considerations, and others. Only in a few cases the client felt that she did not have a personal reason to use contraception and attributed the decision to the husband or family (4 percent) or to the provider ( 5 percent). In most cases she made the decision and then visited the health post to seek the services. In others, the provider suggested contraception during a consultation or the idea emerged as she received a home visit. When asked who had the initiative, the client attributed it to the provider in 23 percent of the cases.

The choice of specific method was made in a context of counseling received from the provider. Yet none of the items referring to information received about specific methods reach the LQAS standard despite that some are associated with high levels of occurrence. It may be impossible to establish the individual weight of the most likely causes: client memory lapses or provider failures. It is known that clients soon forget a significant portion of what they learned in a consultation (León et al., 1990).

At any rate, the central finding is that the client chose the method. A minority of providers exerted pressure in favor of a specific method; a survey of providers may have been required to determine whether this reflected proper medical considerations or personal biases. Nineteen clients did not receive the method chosen, generally because the provider considered it inappropriate to her case. 
Table 34. Informed Choices: Results of Rural Follow-Up

\begin{tabular}{|c|c|c|c|}
\hline$\underline{\text { LQAS }}$ & $\underline{\text { Item }}$ & $\underline{\%}$ & $+1-$ \\
\hline \multirow[t]{6}{*}{ A } & Client decided to use contraception owing to family size, economy, health & 90 & 6 \\
\hline & Context: Client visited the facility to seek contraception & 64 & 9 \\
\hline & Context: Provider suggested contraception at a consultation & 25 & 8 \\
\hline & Context: The idea emerged during a domiciliary visit & 10 & 6 \\
\hline & Client's attribution of the initiative : Herself/himself & 76 & 8 \\
\hline & Client's attribution of the initiative: The provider & 23 & 8 \\
\hline \multirow[t]{8}{*}{ A } & Provider counseled client on how to use contraception & 90 & 6 \\
\hline & Provider talked about the injectable & 86 & 6 \\
\hline & Provider talked about the pill & 86 & 6 \\
\hline & Provider talked about the IUD & 70 & 8 \\
\hline & Provider talked about the condom & 50 & 9 \\
\hline & Provider talked about VSC & 38 & 9 \\
\hline & Provider talked about the vaginal tablet & 37 & 9 \\
\hline & Provider talked about rhythm & 18 & 7 \\
\hline \multirow[t]{3}{*}{ A } & The client chose the method & 87 & 6 \\
\hline & Provider exerted pressure in favor of a given method & 18 & 7 \\
\hline & Client did not receive the method chosen & 17 & 7 \\
\hline
\end{tabular}

\section{General Family Planning Knowledge}

Each client was asked the same questions of the exit interview about eight family planning methods, and the interviewers registered whether she or he had produced an spontaneous or aided correct answer. Table 35 shows the corresponding raw percentages and whether the item attained the LQAS standard. Generally, the knowledge was inferior to that shown in the exit interviews at urban health centers. Spontaneous correct responses pertaining to the pill and injectable are prevalent enough to attain the LQAS standard. Like in the case of the exit interviews, this can be understood as a result of (a) the fact that most of the informants were users of these hormonal methods and (b) method shifting from pill to injectable and vice versa prevails in the user population (Noble et al., 1998). 


\section{Method Chosen for Further Inquiry}

One method was chosen for further inquiry: the method the client was using at the moment of the interview. If the client was a discontinuer, the inquiry referred to the method the client was given when she/he was enrolled as a new user at the health post. The inquiry pertained to the injectable (53 percent of the cases), pill (17 percent), vaginal tablet ( 9 percent), condom (6 percent), IUD ( 5 percent), rhythm ( 4 percent), lactational amenorrhea ( 3 percent), and VSC ( 1 percent).

\section{Table 35. General Family Planning Knowledge: Results of Rural Follow-Up}

\begin{tabular}{|c|c|c|c|}
\hline$\underline{\text { Item }}$ & $\underline{\text { Spontaneous }}$ & $\underline{\text { Aided }}$ & Either \\
\hline Rhythm method requires abstinence or protected intercourse on some days & 48 & 19 & 64 \\
\hline Fertile interval starts at about $8^{\text {th }}$ day of the cycle and lasts 10 to 12 days & 28 & 17 & 46 \\
\hline Condom is placed on penis before starting intercourse & 52 & 25 & 76 \\
\hline Condom protects against sexually transmitted diseases & 41 & 16 & 57 \\
\hline Vaginal tablet is inserted in vagina before intercourse & 42 & 16 & 58 \\
\hline Vaginal tablet is inserted about 15 (10 to 60 ) minutes before intercourse & 34 & 8 & 42 \\
\hline Pill is taken every day & & 5 & \\
\hline There is a risk of pregnancy if pill is not taken every day & 74 & 10 & 83 \\
\hline The injectable is applied every 3 months & & 3 & \\
\hline Menstrual alterations are the main side effects of the injectable & 37 & 33 & 70 \\
\hline The IUD is inserted into the uterus & 49 & 21 & 70 \\
\hline The IUD lasts 10 years ( 8 years accepted) & 25 & 6 & 31 \\
\hline The sterilized woman will not have more children & 45 & 33 & 78 \\
\hline There is some risk of complications in tubal ligation & 8 & 29 & 37 \\
\hline The vasectomized man will not have more children & 46 & 24 & 70 \\
\hline 3 months or 20 ejaculations are required for effective vasectomy & 5 & 4 & 10 \\
\hline
\end{tabular}

Included in the section of the questionnaire dealing with method chosen for further inquiry were questions about general characteristics of the method, usage instructions, and practical requirements of the client. Table 36 offers the relevant results in terms of number of items known, using criteria similar to those used with exit interview data. Clients offered at least one aided correct response about the method chosen. A high percentage of cases, 78 percent, offered a spontaneous 
correct response but this was not enough to reach the LQAS standard. When either spontaneous or aided correct responses are considered, the conclusion is that clients know three general-information items about the method chosen for further inquiry. These results are similar to those of the exit interviews at urban health centers.

Table 36. General Knowledge about Method Chosen: Results of Rural Follow-Up

Number of Items
One or more
Two or more
Three or more
Four or more

Table 37 offers results concerning the side effects of the method chosen for further inquiry. When either spontaneous or aided correct responses are considered, clients demonstrate that they recall one side effect of its method. As shown in Table 38, client knowledge concerning contraindications was similar to that pertaining to side effects.

Table 37. Knowledge about Side Effects of Method Chosen: Results of Rural Follow-Up

\begin{tabular}{lccc} 
Number of Items & Spontaneous & $\underline{\text { Aided }}$ & \multicolumn{1}{c}{ Either } \\
One or more & 61 & 64 \\
Two or more & 15 & 46 \\
Three or more & 5 & 23 \\
Four or more & 0 & 48 \\
\hline
\end{tabular}

Table 38. Knowledge about Method Contraindications: Results of Rural Follow-Up

\section{$\underline{\text { Number of Items }}$}

One or more

Two or more

Three or more

Four or more

\section{Spontaneous}

26

1

0

0 $\underline{\text { Aided }}$

63

30

11

4
Either

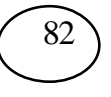

35

12

5 
Clients showed more knowledge concerning when to return to the facility than about method side effects or contraindications (see Table 39).

Table 39. Knowledge about Follow-Up: Results of Rural Follow-Up

\begin{tabular}{|c|c|c|c|}
\hline$\underline{\text { Number of Items }}$ & $\underline{\text { Spontaneous }}$ & Aided & Either \\
\hline One or more & 76 & & 10 \\
\hline Two or more & 18 & 64 & 83 \\
\hline Three or more & 2 & 26 & 66 \\
\hline Four or more & 0 & 7 & 30 \\
\hline
\end{tabular}

Generally, user knowledge about the method chosen in rural sites was less prevalent than among clients of urban health centers. Nevertheless, the structure of knowledge was similar: greater knowledge about how to use method than about contraindications or side effects.

Only 17 percent of the clients felt that they had all the information needed to use their method. This statement, however, was obtained after all the knowledge questions had been formulated and may have been influenced by this fact.

\section{RELIABILITY}

The consistency of the quality-of-care measurements was evaluated in the context of LQAS methodology and having the SDP as the unit of analysis. A part-total approach was implemented, which required comparison of the results stemming from the full set of data (six cases per facility at 19 facilities) with findings obtained from a restricted subset (one case per facility at 19 facilities). To this end, one case was randomly chosen from each set of six.

Table 40. Achievement of LQAS Standard by Number of Cases per Facility, Service Test Form A (over 50 items)

\section{One Case per Facility}

Achieves Standard Fails to Achieve It

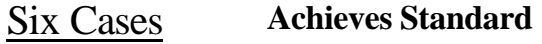

$\underline{\text { Per Facility }}$

Fails to Achieve It
17

10
0

23 $p_{1}=.34$

$q_{1}=.66$

$p_{2}=.54 \quad q_{2}=.46$ 
The responses under the total versus part measurement approaches generated a $2 \times 2$ table for each instrument, of the form shown in Table 40 - which compares results over the 50 items of the Service Test used in hospitals. These tables were used to calculate the degree of agreement between the two approaches, which is represented in the table by the cells in the diagonal. The index of crude agreement (ICA) is the proportion of all cases in which the classifications agreed either Yes-Yes or No-No, i.e., 17 (cell $a$ ) +23 (cell $d$ ) / 50. The ICA for the data in Table 40 is .80 .

Table 41 offers the contingency tables for the five instruments of the study. In the five tables, cell $b$ is empty; that is, there was not a single item that achieved the LQAS standard on the basis of six cases per facility and failed to achieve it on the basis of one case. This suggests that a single case per facility may cause false positives (achieve the LQAS standard when it is not achieved on the basis of six cases) but not false negatives (fail to achieve the standard when it is achieved on the basis of six cases).

Table 41. Part-total contingency tables (cells $a, b, c, d)$ and $p$ and $q$ values for the five instruments of study

\begin{tabular}{lcccccccc}
\hline Instruments & $\underline{\mathbf{a}}$ & $\underline{\mathbf{b}}$ & $\underline{\mathbf{c}}$ & $\underline{\mathbf{d}}$ & $\underline{\mathbf{p}_{1}}$ & $\underline{\mathbf{q}_{1}}$ & $\underline{\mathbf{p}_{2}}$ & $\underline{\mathbf{q}_{2}}$ \\
Service Test Form A (Hospitals) & 17 & 0 & 10 & 23 & .34 & .66 & .54 & .46 \\
Follow-Up of Sterilized Patients (Hospitals) & 12 & 0 & 8 & 21 & .29 & .71 & .49 & .51 \\
Service Test Form B (Health Centers) & 26 & 0 & 2 & 33 & .43 & .57 & .46 & .54 \\
Client Exit Interview (Health Centers) & 18 & 0 & 7 & 18 & .42 & .58 & .58 & .42 \\
Follow-Up of Rural Users (Health Posts) & 16 & 0 & 12 & 27 & .29 & .71 & .51 & .49 \\
\hline
\end{tabular}

A limitation of ICA is that it takes neither chance agreement nor skewness into account. The skewness of a variable is taken by calculating its average, i.e., p. For example, the skewness of the six-case classification in Table 40 is .34 . The closer the average is to 0 or 1 , the more skewed the variable, and the closer to .50 , the less skewed the variable. The more skewed the variable, the greater the possibility that the two measurements will agree simply by chance. Hence, we used a second measure of agreement, the kappa statistic (Cohen, 1960), which corrects for chance agreement. Kappa is the proportion of possible agreement that the measurements achieved above what chance alone would predict. In the case of perfect agreement, kappa equals one; it equals zero if the observed agreement equals the expected agreement. The kappa for the data in Table 40 is .61.

Figure 2 depicts the distribution of kappa over the instruments used in this study. The Service Test Form B shows a very good reliability (kappa $=.93$ ). The other instruments show less satisfactory kappas. The superiority shown by the Service Test Form B may be explained by a combination of factors: (a) use of trained observers instead of untrained users as sources, (b) a less complex staff infrastructure in health centers than in hospitals, and (c) a less complex service delivery for the client interested in a reversible method than for the client interested in sterilization. 
Figure 2 Kappa for the Six Instruments Employed in the Assessment of the Quality of Care at Peru MOHFacilities

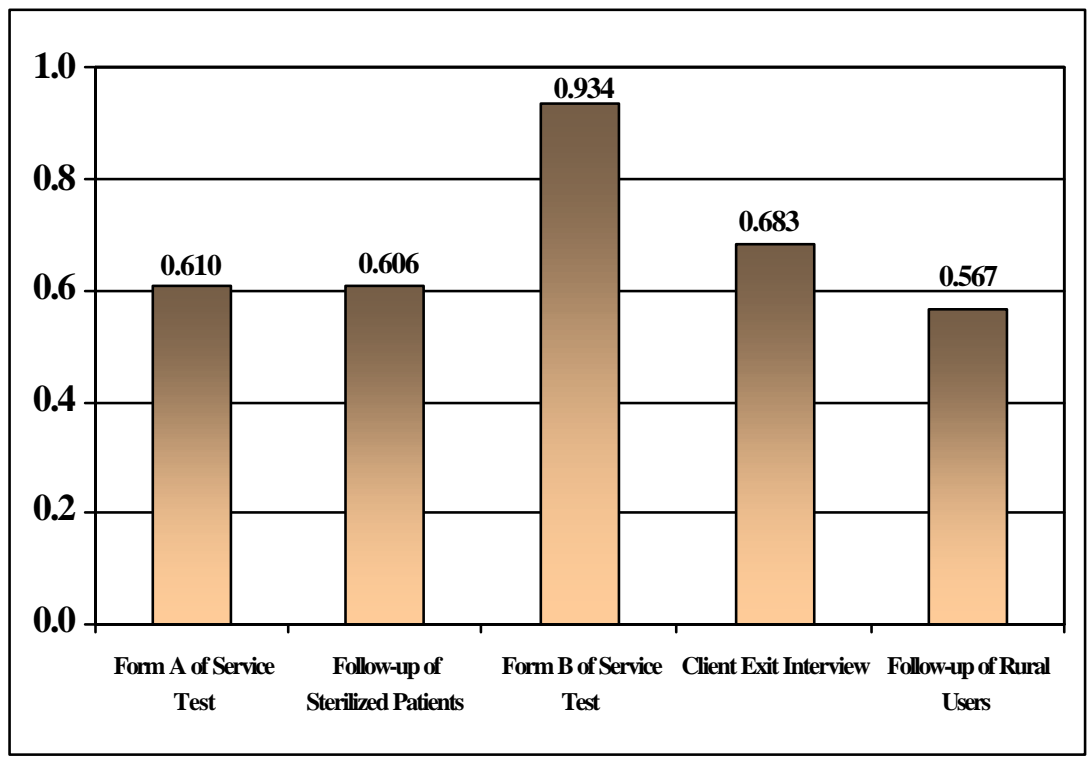

Another question of interest in the reliability domain is whether the various items of a checklist or questionnaire are intercorrelated and thus justify the summation of the respective item scores (1s and 0s). If this is the case, a synthetic, global quality of care score can be obtained for each case.

Cronbach's (1951) alpha coefficient was used to assess the internal consistency of the checklists and questionnaires used in this study. The highest alphas were associated with the Sterilization Follow-Up Questionnaire (.86) and Form B of the Service Test used in health centers (.82), followed by the Rural Follow-Up Questionnaire (.79), Form A of the Service Test used in hospitals (.77), and the Client Exit Interview (.74). These coefficients are not high enough to justify the use of a summated score to make decisions concerning individual providers. However, the summated scores are consistent enough to justify their use for evaluation purposes at group level.

\section{E. COST AND COST-EFFECTIVENESS}

The cost study focused on the individual components of the monitoring system and implemented a comparative analysis. The purpose was to calculate the cost of replicating each of the components such that the $\mathrm{MOH}$ could in the future use a monitoring system streamlined on the basis of its reliability and cost.

Table 42 refers to the direct costs of implementing each instrument. These exclude the activities that were in charge of the Principal Investigator (developing the methodological approach, writing the project proposal, negotiating its approval, designing the instruments, supervising the conduct of the study, analyzing the data, drafting preliminary partial reports and the final report, and making oral presentations of the findings) and can best be conceived of as generating indirect costs.

Direct personnel costs include payments to data collectors (simulated clients, interviewers), field supervisors, and research assistants (who assisted in training of data collectors, instrument development and testing, and data analysis), as well as two field coordinators. One of the latter (Rosa Monge) assisted in the construction of Service Test instruments, trained simulated clients, and 
Table 42. Direct Costs in U. S. Dollars of Implementing Each of Five Instruments

\begin{tabular}{|c|c|c|c|c|c|}
\hline$\underline{\text { Item }}$ & $\frac{\text { Service Test }}{\underline{\text { Form A }}}$ & $\frac{\text { Follow-Up of }}{\underline{\text { Sterilizations }}}$ & $\frac{\text { Service Test }}{\underline{\text { Form B }}}$ & $\frac{\text { Client Exit }}{\underline{\text { Interview }}}$ & $\frac{\text { Follow-Up of }}{\text { Rural Users }}$ \\
\hline Personnel & 13804 & 13791 & 7686 & 7244 & 12616 \\
\hline Transportation & 2061 & 1294 & 1238 & 1371 & 2727 \\
\hline Per diem & 7589 & 2343 & 5386 & 1764 & 5368 \\
\hline Materials & 353 & 254 & 279 & 206 & 309 \\
\hline Other & 1793 & 273 & 1188 & 721 & 765 \\
\hline Total & 25599 & 17955 & 15777 & 11306 & 21685 \\
\hline
\end{tabular}

coordinated their work. The other (María Rosa Gárate) assisted in the construction of follow-up questionnaires, trained the interviewers, and coordinated their work. They shared responsibilities concerning implementation of Client Exit Interviews. Administrative costs are not considered.

Transportation costs involved air travel across provinces and land travel within provinces. Perdiem was most expensive when six different simulated clients had to visit the same facility, particularly if they had to stay for several visits (Service Test in hospitals), and when interviewers had to perform rural household visits. Materials were basically the checklists and questionnaires. Other expenses included office space for training and communications.

The least expensive instrument was the Client Exit Interview because a single interviewer was able to complete rather rapidly the six interviews required at each health center and move on to the next facility. The most expensive instrument was the Service Test used in hospitals, which required that six different simulated clients visit each hospital and that each simulated client perform several visits to the same hospital.

Since this study used Lot Quality Assurance Sampling, kappa was selected as the reliability indicator to construct an index of cost-effectiveness. Figure 3 shows the distribution of the index of cost-effectiveness over the five instruments. To construct this index, a cost per case was calculated dividing the total cost of implementing the instrument by the number of cases yielded (114); then the cost per case was divided by the respective kappa, expressed in percentage points rather than as a proportion. Hence, the cost-effectiveness index measures the cost of achieving a reliability point. For example, the $\$ 25,599$ used in implementing the Service Test in hospitals, divided by the 114 cases produced and then by the 61 reliability points associated with this instrument, generates a cost of $\$ 3.68$ per reliability point. The Client Exit Interview and the Service Test Form B are the most cost-effective instruments. 
Figure 3. Cost-Effectiveness of Six InstrumentsEmployed in the Assessment of the Quality of Care at Peru MOHFacilities

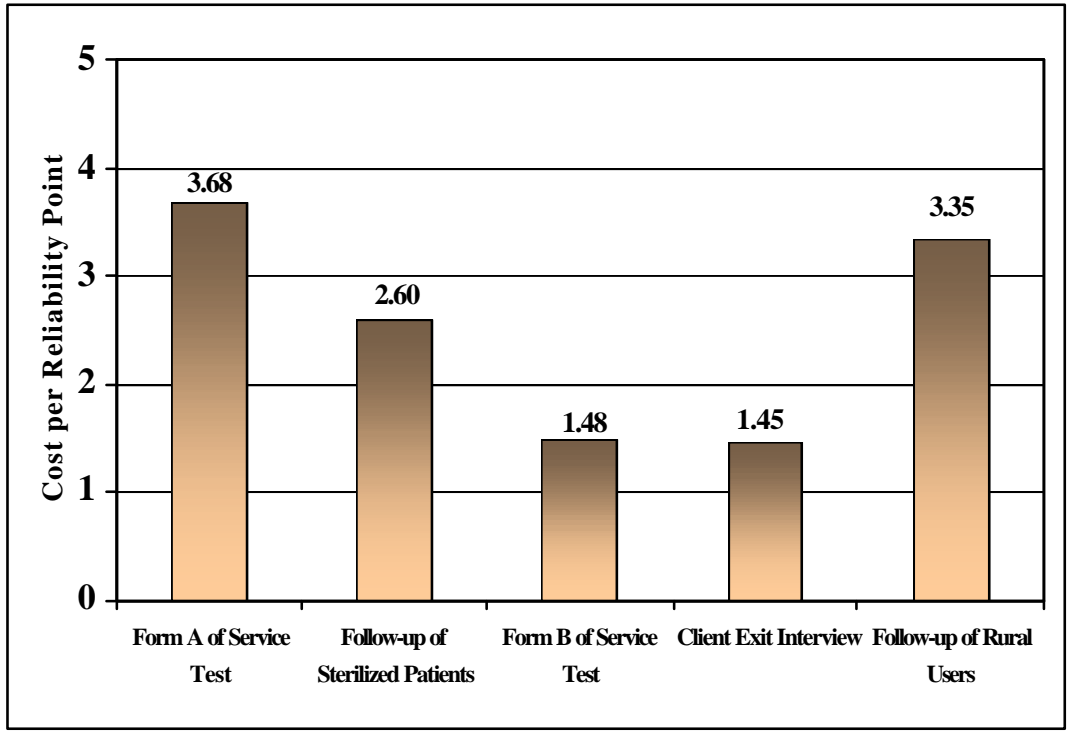




\section{DISCUSSION}

The sampling strategy implemented in this study offers considerable practical advantages in terms of the scope of its coverage and the triangulation of data collection instruments. On the other hand, it poses some limitations to the external validity of the specific findings. The Service Test and follow-up findings from Sample I can only be generalized to the largest hospitals encompassed in the Reporting Units of the National Family Planning Program that performed the largest numbers of sterilizations in 1998. The Sample II Service Test and exit interview findings can only be generalized to the largest health centers of the middle segment of Reporting Units. The Sample III follow-up findings can only be generalized to the rural health posts of the lower segment of Reporting Units. Another problem is that the Reporting Units had different numbers of facilities, which was compensated in part by their weighted sampling.

The main advantage of the sampling approach used was that if consistent findings were found across such different samples, and over the diverse instruments implemented in the study, they could be generalized country-wise with little uncertainty. Fortunately, the findings of this study were rather consistent, revealing that providers treat clients respectfully and dedicate considerable part of the counseling process to offer an unbiased set of contraceptive options. On the other hand, they are not exhaustive in screening clients for contraindications, give them limited information concerning action mechanisms and side effects of the method chosen, and are not exhaustive informing them about usage instructions and follow-up.

\section{The Observational Evidence}

The results of the Service Test do not provide a simple answer to the question, "Do health centers and hospitals of the Peru $\mathrm{MOH}$ give an informed choice of methods to clients?" Providers at health centers gave a choice in the sense that they offered a wide variety of methods to the client. For their part, providers at hospitals did not bias the choice in favor of a given method. But the choice was far from being sufficiently informed. For example, providers avoided talking exhaustively to the client about the side effects of DMPA or about the risk of complications in the sterilization procedure. The finding of nearly universal free-choice attitudes on the part of the providers is consistent with the National Family Planning Program's goal of establishing a policy of free choice of methods. On the other hand, the limited screening found for contraindications and scarce information given to the client are technical challenges that the Program needs to address. Provider compliance with MOH standards concerning the use of the VSC Request Form and the 72hour reflection period between last counseling and surgical intervention was particularly limited.

Evidently, these conclusions are stated in reference to the stringent quality of care standards used in this study. In a number of instances, satisfactory provider behavior was observed in as many as 70 percent of cases or more and yet did not meet the LQAS standard of 95 percent of cases receiving adequate care in each facility and 80 percent of the facilities satisfying this requirement. These standards have been used worldwide in several LQAS applications (Valadez et al., 1997). Had the definition of quality of care standards been somewhat less demanding more positive conclusions would have been obtained.

However, the results of this study do compare favorably with observational findings reported 
elsewhere. In a Situation Analysis study of the Nairobi City Commission clinics, Mensch et al. (1994) reported that less than 50 percent of new family planning clients were provided with contraindication or side-effect information about their method. ${ }^{10}$ Kim et al. (1998) audiotaped family planning counseling sessions in Kenya and reported that only 57 percent of clients who received the injectable and 32 percent of clients who received the pill were provided with information concerning their respective side effects. According to Situation Analysis studies conducted in 12 African countries, the percentage of family planning acceptors who were told how to use their method and its side effects ranged from 5 percent in Tanzania and 22 percent in Burkina Fasso to 64 percent in Kenya and 68 percent in Bostwana (Miller et al., 1998). In a similar study conducted in Ecuador, Uganda, and Zimbabwe, Bertrand (1999) found in each country that in less than 75 percent of the cases the provider gave the client any information about the method received. In our Peru study, more than 80 percent of the providers gave the client information about the method chosen. Even though the findings from these studies are not strictly comparable ${ }^{11}$, the Situation Analysis results suggest that the family planning services offered in the sites in Africa and Ecuador are of a lower quality than those offered at Peruvian health centers and hospitals.

The Service Test has generated systematic data in Ecuador. In an application on a national sample of facilities encompassing 25 hospitals and 74 health centers, León et al. (1998) implemented a client profile of a recently initiated pill user who had headaches and solicited counseling about method shifting. Only 53 percent of the providers told the simulated client that the headaches might be a side effect of the pill and only 39 percent told her that it might disappear in a few months. These findings confirm the international practice to give limited information to clients. León (1997) used a similar Service Test client profile in a study of 54 providers in the province of Santa, Peru. More than 70 percent of the providers told the simulated client that the headache might be a side effect of using the pill and more than 67 percent told her that it could disappear shortly. Whereas the samples are not strictly comparable (one is a national sample and the other is circumscribed to a highly industrialized coastal area) and the statistical basis for the comparison may be called into question, the results are consistent with the suggestion that Peruvian providers offer a higher quality of care than other providers in the Andean region.

Longitudinal comparisons within Peru do not lend themselves to inferences about the progress made in recent years. Del Valle et al. (1993) conducted a Situation Analysis study in which both new family planning clients and continuers, as well as private and public sector facilities, were confounded. Figueroa et al. (1997) performed a rapid diagnostic study of communication needs in MOH's hospitals, health centers, and health posts; yet the family planning cases represented a minority of the consultations, the majority entailing maternal health. The Service Test study conducted in Santa (León, 1997) was limited to an area of the Peruvian coast. Finally, an earlier study using the Service Test (León et al., 1994a) was conducted in rural and semi-rural areas of Peru and involved nonprofessional providers. To observe longitudinal trends it is necessary to repeat the same measures on comparable samples of providers.

\section{The Evidence as Reported by Clients}

Home follow-up interviews with clients sterilized at hospitals demonstrated that a majority of the tubal ligations are performed in the postpartum (a quarter of them under cesarean section). Clients receive counseling before the surgical procedure and choose permanent contraception 
knowing that they will never have more children. In the view of clients, providers systematically advise clients about two essential things: the infertility consequence of sterilization and that the hospital services are free. Clients recall signing at least one form before the surgical procedure (yet not its contents) and being given an appointment to return to the hospital after it. They are satisfied with the services, although some experience regret later.

The exit interviews with users of family planning services at health centers in urban areas were complementary to the observations obtained from simulated clients at those facilities. Whereas the simulated clients enacted the client profile of a new client, the majority of the real clients tapped by the exit interviews were continuers. Hence, the exit interviews primarily sought to establish the extent of their family planning knowledge. In the interviews, clients showed that they knew that the injectable is applied every three months and causes menstrual alterations, that the pill is taken every day and failure to do so increases the risk of pregnancy, that sterilized women will not have more children, and that the condom is placed in the penis before intercourse. The presence of the last two items in the memory of the clients, most of whom were users of the injectable or the pill, suggests that a contraceptive culture is expanding in Peru. With respect to the method currently used, clients know more about its usage instructions and other general characteristics (3 items) and about followup (3 items) than about their contraindications (1 item) or side effects ( 1 item). This finding is consistent with the reports from simulated clients, who found that providers emphasized usage instructions and follow-up and were less informative about contraindications or side effects.

Home follow-up interviews with users of rural health posts revealed lesser client knowledge, limited to the pill items and the frequency of the injection. However, the urban-rural difference is only one of magnitude: rural clients also showed greater knowledge concerning usage instructions and general characteristics and follow-up than contraindications or side effects of the method chosen for further inquiry. Like the urban clients, they used mainly the injectable, secondarily the pill, and then the other methods. In addition to knowledge, the follow-up of rural clients tapped memories of the client-provider interaction process. The results revealed that rural clients decided on their own to use contraception and chose the family planning method. Providers did not pressure them to choose a given method.

Clients positively regarded provider interpersonal behavior in the three settings. Privacy was maintained in health centers and posts but not in hospitals. Generally, the findings at health centers and hospitals are consistent with the observations of simulated clients in the Service Test. The main knowledge deficits had to do with contraindications and side effects, which do not generally prevent the client to use the method properly. In the revisits to give feedback to providers, they attributed these failures to time constraints. In the consultations at health centers, more than 60 percent of the client-provider interactions lasted less than 15 minutes, generally because the provider had to dedicate time to other clients. Regardless of total time invested, however, providers dedicated more time to talk about the diverse methods available than about the one chosen by the client. A more balanced counseling approach is needed to assure adequate quality of care.

Our general conclusion from this study is that the quality of care at MOH's facilities leaves considerable room for improvement. However, there is no evidence of systematic violations of the essential rights of clients. The cases of greatest concern in this respect entailed (a) a woman with pre-eclampsia who underwent a cesarean partum after receiving VSC counseling during her pre-natal 
visits and who may or may not have been serilized. (If sterilized, it was without her consent, for she was unconscious, but with the consent of her brothers; see Appendix F.) And (b) two women who said that, prior to the surgical procedure, they did not know that sterilization results in the loss of the capacity to have more children. The latter did not express sterilization regret. On the other hand, there are doubts concerning the reliability of these case-data. These cases would have to be viewed as exceptions which contrast with the overwhelming majority of cases in which the essential rights of clients were respected.

\section{Reflections on the Monitoring System}

Some findings of this study are relevant to practical concerns pertaining to the monitoring system that the $\mathrm{MOH}$ could use for the periodic follow-up of the quality of care offered at its facilities. The Service Test applied in hospitals (Form A) was expensive, not quite reliable, and cumbersome; the VSC counseling was difficult to observe throughout all its phases and some simulated clients had to perform three or four visits to the hospital. The home follow-up interviews proved to be expensive, not quite reliable, and incomplete; many cases were lost because of problems to locate clients and had to be replaced, posing limitations to the interpretation of the data.

The Service Test Form B and Client Exit Interviews were less expensive and more reliable, suggesting that the monitoring system would improve its general reliability if it were limited to tapping health centers with these instruments. Yet, significant aspects of family planning service delivery such as the VSC process would be left untouched and the rural population would be excluded. Before deciding to concentrate in health centers, it may be worthwhile to undertake initiatives to improve the reliability and practicality of the measures used in hospitals and rural health posts.

To reduce costs, the $\mathrm{MOH}$ could consider monitoring the quality of care on the basis of a reduced battery of instruments frequently replicated (e.g., quarterly) and with the whole battery more sparsely replicated (e.g., annually). The Service Test Form B can be used in health centers at the rate of one case per facility. This form attained a reliability level justifying the use of a single case per facility instead of the six cases implemented in the study. Applying the Service Test at the rate of one case per health center might bring fourfold reductions in its cost. On the other hand, the evaluation system might have to exclusively rely on LQAS; confidence intervals based on 19 cases may be too wide to be of any practical value. 


\section{UTILIZATION}

The findings of the study were utilized by USAID/Peru and the MOH before the project was

formally completed and are expected to be further utilized by the MOH later on in 1999-2000.

Preliminary written reports were circulated on July 30 (about the Service Test findings) and August 31 (about the client interviews) to USAID/Peru and the $\mathrm{MOH}$, and additional oral presentations were made to the USAID/Peru's Director, Health/Population/Nutrition (HPN) Chief, Mission legal counsel, other HPN staff, and other Mission staff on August 3 and September 2. Of particular concern to USAID/Peru was the interpretation of the findings in the light of the Tiahrt Amendment, which was enacted in the 1999 Foreign Operations Appropriations Act of the U. S. Congress. The discussions centered on the extent to which the findings contradicted one of the Amendment's requirements: that acceptors get comprehensible information on health benefits and risks of the method chosen, including conditions that might make the method chosen inadvisable and known adverse side effects.

As a consequence of the study, USAID/Peru and the Peru MOH agreed that the former withheld its family planning assistance until the $\mathrm{MOH}$ took certain steps to improve the quality of care. The $\mathrm{MOH}$ published the new quality of care norms, circulated them at national level, and strengthened its provider retraining efforts, and the assistance was restablished. 


\section{CONCLUSIONS AND RECOMMENDATIONS}

\section{Conclusions}

$>$ One of the strongest elements of care is that of interpersonal relationships. Providers treat clients with respect and attempt to ensure privacy during client-provider consultations.

Another strong element is that of free choice of methods. Providers inform clients about a variety of contraceptive methods and do not betray systematic biases in favor or against particular methods.

> Significant shortcomings are observed in the client's screening for contraindications. Providers generally limit the screening to questions about last menstruation to ensure that the woman is not pregnant.

$>$ Another critical area is that of information given to the client. Providers are particularly reticent when it comes to talk about the adverse effects of the methods. Consequently, clients generally make their method choices on the basis of very limited information.

Another consequence of the provider's reserve is that clients leave the consultation knowing only the basic instructions to use the method and very little about the contraindications and sideeffects of the method chosen.

$>$ In handling sterilization cases, providers show insufficient compliance with MOH standards concerning use of the VSC Request Form and the 72-hour reflection period between last counseling and surgical intervention.

\section{Recommendations}

Providers must be given clear task goals prioritizing the quality of care. This can be done through IEC materials, training, and supervision.

$>$ The counseling strategy ought to become more balanced. Providers should talk less about less relevant methods and more about the method chosen by the client.

$>$ Providers should receive task performance feedback. The findings of this study should be disseminated to Family Planning Coordinators and, through them, to individual providers.

> Supervisors should evaluate client-provider interactions with the level of detail of the tables used in this report and ought to give systematic feedback to providers.

$>$ Organizational rewards and punishments should be consistent with provider task performance evaluated periodically. 


\section{NOTES}

${ }^{1}$ New to the facility or continuer in the use of its services.

2 The presence of nurses and interns during counseling was considered a violation of privacy. Their presence in the operating room was not.

${ }^{3}$ To test the hypothesis that provincial hospitals performed the pelvic exams but provincial simulated clients avoided them, simulated clients who had reported receiving pelvic examinations in Lima were sent to the provincial hospitals which had failed to perform such exams according to the provincial simulated clients. The Lima simulated clients confirmed that the provincial hospitals did not perform pelvic exams.

${ }^{4}$ Given the technical nature of the topic and the time elapsed, the responses of the sterilized women would have been unreliable.

${ }^{5}$ A preliminary report of the Service Test findings of this study erroneously reported a 2 percent response for this item.

${ }^{6}$ In some cases the 72-hour reflection period may hinder the quality of care in the client's perspective. This is why the provider has the option to waive this requirement if requested by the client.

${ }^{7}$ This was not suggested by the provider but ocurred to the simulated client.

${ }^{8}$ The confidence intervals are wider when the percentage is close to 50 and narrower when it is close to 0 or 100 .

${ }^{9}$ When separate analyses are performed for DMPA users alone, the spontaneous responses pertaining to the side effects of the the injectable increase.

${ }^{10}$ Brown et al. (1995) did not report on these facets in their Situation Analysis study in Morocco.

${ }^{11}$ There are sampling problems affecting these comparisons, and the Bertrand's (1999) data confounded new family planning clients and continuers. It should also be noted that the observations obtained from audiotapes or offered by professional observers of the client-provider interaction pertain to situations in which the provider was motivated to exhibit maximal performance.

\section{ACKNOWLEDGMENTS}

Special recognition is deserved by the consultants and research and administrative staff of the Population Council's Peru Office who enabled FRONTIERS to meet the project goals on a tight schedule. 


\section{REFERENCES}

Bertrand. J. T. (1998) "Quality Index: An approach to monitoring quality of care in family planning \& reproductive health programs." Discussion Draft. MEASURE Evaluation Project.

Bertrand, J. T. (1999) "Prueba de campo conducida en varios países sobre indicadores de calidad de atención en programas de planificación familiar en clínicas." Presentation at a meeting with Peruvian reproductive health professionals. Lima: Population Council, 17 June.

Brown, L., M. Tyane, J. T. Bertrand, D. Lauro, M. Abou-ouakil, \& L. de María (1995) "Quality of care in family planning services in Morocco." Studies in Family Planning 26, 3: 154-168.

Bruce, J. (1990) "Fundamental elements of the quality of care. A simple framework." Studies in Family Planning 21, 2, 61-91.

Cáceres, C., \& E. Villanueva (1997) "Comportamiento del proveedor en la consulta de planificación familiar." In F. R. León, Quality of care and user outcomes in the province of Santa, Peru: 1. A diagnostic study with focus on providers. Final Report of INOPAL III Sub-Project. Lima: Population Council.

Cohen, J. A. (1960) "Coefficient of agreement for nominal scales." Educational and Psychological Measurement 20, 37-46.

CRLP (1999) Silence and complicity: Violence against women in Peruvian public sectyor facilities. New York: The Center for Reproductive Law and Policy.

Crombach. L. (1951). "Coefficient alpha and the internal structure of tests." Psychometrika 16:297334.

Del Valle, D., M. R. Gárate, J. R. Foreit, D. Li, F. Murillo, A. Mongrut, J. Nagahata, J. Gilman, \& C. Gutiérrez (1993) Encuesta de disponibilidad de servicios de planificación familiar. EDIS-Perú, 1992. Lima: Ministerio de Salud, Instituto Nacional de Estadística e Informática, Asociación Benéfica PRISMA, and Population Council.

Espinoza, I. A., R. Fernández, \& M. García (1999) "Estudio de los factores que influyen en la satisfacción de los varones sometidos a la anticoncepción quirúrgica voluntaria - DISA III Lima Norte, 1997." Tesis de Licenciado en Enfermería. Lima: Universidad Peruana Cayetano Heredia, May.

Franco, L. M., C. C. Daly, D. Chilongozi, \& G. Dallabetta (1997) "Quality of case management of sexually transmitted diseases: Comparison of the method for assessing the performance of providers." Bulletin of the World Health Organization, 75, 6, 523-532.

Hermida, J., D. Nicholas, \& S. Blumenfeld (1996) "Comparative validity of three methods for the assessment of the quality of primary health care: Guatemala field study." Quality Assurance Methodology Refinement Series. Bethesda, Maryland: Quality Assurance Project, Center for Human Services. 
Kim, Y. M., A. Kols, \& S. Mucheke (1998) "Informed choice and decision-making in family planning counseling in Kenya." International Family Planning Perspectives 24, 1: 4-11.

Lanata, C. F. \& R. E. Black (1991) "Lot Quality Assurance Sampling Techniques in health surveys in developing countries: Advantages and current constraints." World Health Statistics Quarterly, 44: 133-139.

Lemeshow, S., \& S. Taber (1991) "Lot Quality Assurance Sampling: Single- and double-sampling plans." World Health Statistics Quarterly, 44: 115-132.

León, F. R. (1997) Quality of care and user outcomes in the province of Santa, Peru: 1. A diagnostic study with focus on providers. Final Report of INOPAL III Sub-Project. Lima: Population Council.

León , F. R., J. R. Foreit, R. Monge, E.Mostajo, E. Ortíz, \& M. Ramos (1990) "An experiment to improve the quality of care in a Peruvian community-based distribution program." Final Report of INOPAL II Sub-Project. Lima: Population Council.

León, F. R., R. Hurtado, R. Monge, A. Mongrut, T. Watanabe, M. E. León, J. Parra, \& I. Ramos (1994a) Mejorando la calidad y acceso a servicios de planificación familiar en ámbitos rurales y semi-rurales del Perú. Lima: Instituto Andino de Estudios en Población y Desarrollo (INANDEP).

León, F. R., G. Quiroz, \& A. Brazzoduro (1994b) "The reliability of simulated clients' quality-ofcare ratings." Studies in Family Planning 25, 2, 184-190.

León, F. R., M. E. Costa, P. Jácome, E. Ottolenghi, M. Espinoza, R. Monge, J. Ordóñez, \& W. Ventosilla (1998) "Developing algorithmic instruments to help providers and users to implement the new reproductive health care guidelines issued by the Ministry of Public Health of Ecuador". Final Report of INOPAL III Sub-Project. Lima: Population Council.

Mensch, B. S., R. A. Miller, A. A. Fisher, J. Mwita, N. Keyonzo, F. Y. M. Ali, \& C. Ndeti (1994) "Family planning in Nairobi: A Situation Analysis of the City Commission clinics." International Family Planning Perspectives 20: 48-54.

MEASURE Evaluation Project (1998) Monitoring and Evaluation Sub-committee of MAQ. July.

Miller, K., R. A. Miller, I. Askew, M. C. Horn, \& L. Ndhlovu (1998) Clinic-based family planning and reproductive health services in Africa: Findings from Situation Analysis studies. New York: Population Council.

Miller, R. A., L. Ndhlovu, M. M. Gachara, \& A. A. Fisher (1991) "The situation analysis study of the family planning program in Kenya." Studies in Family Planning 22, 3, 131-143.

Miller, R., A. Fisher, K. Miller, L. Ndhlovu, B. Ndugga Maggwa, I. Askew, D. Sanogo, \& P. Tapsoba (1997) The Situation Analysis approach to assessing family planning and reproductifve health services: A handbook. New York: Population Council.

MOH (1989) Manual de normas y procedimientos en planificación familiar. Lima: Ministerio de 
Salud.

MOH (1992) Manual de salud reproductiva: Métodos y procedimientos. Lima: Ministerio de Salud.

MOH (1995) Programa de salud reproductiva y planificación familiar: 1995-2000. Lima: Ministerio de Salud.

MOH (1998a) Directiva DGSP-DPS-PF-No. 001-98 (Asunto: Cambios normativos en el Programa de Planificación Familiar. Lima: Ministerio de Salud, March 19.

MOH (1998b) Manual de Esterilización Quirúrgica Voluntaria, 3rd. Ed.. Lima: Ministerio de Salud, December.

MOH (1999) "Normas del Programa de Planificación Familiar. Pre-Publicación." Diario El Peruano. Lima: May 6.

Noble, J. A., I. Ramos, L. Carbajal, F. Iturrizaga, E. Caballero, A. Padilla, \& M. R. Gárate (1998) "Continuiudad en la planificación familiar: Un seguimiento de usuarias de establecimientos públicos de la provincia de Santa." Documento de Trabajo No. 19. México: Population Council.

Pathak, K. B., F. Ram, \& R. K. Verma (1998) "Monitoring and evaluating systems." In S. Pachauri \& S. Subramanian (Eds.) Implementing a reproductive health agenda in India: The beginning. New Delhi: Population Council Regional Office.

Peru-DHS (1997) Encuesta demográfica y de salud familiar 1996. Lima: Instituto Nacional de Estadística e Informática.

Peruvian Congress (1995) Ley No. 26530 que modifica el Artículo VI del Decreto Legislativo No. 346, Ley de Política Nacional de Población, para incluir a la anticoncepción quirúrgica voluntaria ligadura de trompas y vasectomía - como métodos anticonceptivos. Lima: Congreso de la República del Perú.

Ramos, I., \& L. Wong (1997) "Soluciones discutidas con los proveedores." In León, F. R. (1997) Quality of care and user outcomes in the province of Santa, Peru: 1. A diagnostic study with focus on providers. Final Report of INOPAL III Sub-Project. Lima: Population Council.

Salazar, V., \& M. Llajamango (1997) "Usos, actitudes, y conocimientos de las usuarias a la salida de la consulta. In León, F. R. (1997) Quality of care and user outcomes in the province of Santa, Peru: I1. A diagnostic study with focus on clients. Final Report of INOPAL III Sub-Project. Lima: Population Council.

Salazar, X., \& F. Rivero (1997) "Percepciones de las mujeres sobre la calidad de los servicios." In León, F. R. (1997) Quality of care and user outcomes in the province of Santa, Peru: I1. A diagnostic study with focus on clients. Final Report of INOPAL III Sub-Project. Lima: Population Council.

United Nations (1994) Report of the International Conference on Population and Development. Cairo: September 5-13. 
Valadez, J. J. (1991) Assessing child survival programs in developing countries: Testing Lot Quality Assurance Sampling. Harvard Series on Population and International Health. Cambridge, MA: Harvard University Press.

Valadez, J. J., R. Transgrud, M. Mbugua, \& T. Smith (1997) "Assessing service delivery skills in Kenya." Studies in Family Planning 28, 2, 143-150. 


\section{APPENDIX A. SAMPLING}

Sample I. Nineteen Reporting Units were randomly sampled from the list of 49 that performed 150 or more sterilizations in 1998, weighted for number of VSCs. The Loreto Region entered the sample twice owing to its size. The chosen Reporting Units, along with their number of family planning consultations and sterilizations, are listed in Table A1. Their geographical distribution appears on Figure 1 (p. 11). To obtain Sample I, the largest hospital was chosen at each Reporting Unit with the exception of Loreto, which yielded two hospitals. One of the sampling facilities, in Piura, was no longer called a "hospital" but continued to function as such.

Table A1. Reporting Units, Sample I

\begin{tabular}{|c|c|c|c|}
\hline$\underline{\text { Reporting Unit }}$ & $\underline{\text { Department }}$ & $\underline{\text { Number of Consultations }}$ & $\underline{\text { Number of Sterilizations }}$ \\
\hline Loreto Region & Loreto & 45,158 & 1,310 \\
\hline Loreto Region & Loreto & 45,158 & 1,310 \\
\hline S. R. S. Luciano Castillo & Piura & 38,209 & 900 \\
\hline Maternal Institute & Lima & 13,267 & 866 \\
\hline María Auxiliadora Hospítal & Lima & 6,457 & 642 \\
\hline UBASS Chiclayo & Lambayaque & 16,192 & 539 \\
\hline S. R. S. Huancavelica & Huancavelica & 10,653 & 516 \\
\hline Santa Rosa Hospital & Lima & 5,496 & 408 \\
\hline UTES D. A. Carrión & Junín & 11,140 & 405 \\
\hline Cayetano Heredia Hospital & Lima & 8,078 & 361 \\
\hline S. R. S. Chota & Cajamarca & 10,943 & 333 \\
\hline S. R. S. Amazonas & Amazonas & 6,616 & 331 \\
\hline S. B. S. Sergio Bernales & Lima & 1,780 & 320 \\
\hline Zonadis Catacaos & Piura & 15,821 & 275 \\
\hline San José Hospital & Callao & 3,352 & 250 \\
\hline S. B. S. Puente Piedra & Lima & 8,501 & 222 \\
\hline Network Paucarbamba & Huánuco & 6,522 & 202 \\
\hline S. R. S. Lima Este & Lima & 24,920 & 192 \\
\hline Guzmán Barrón Hospital & Ancash & 5,286 & 162 \\
\hline
\end{tabular}


Sample II. Nineteen Reporting Units were randomly sampled from the list of 67 Reporting Units that performed from 40 to 149 sterilizations in 1998, weighted for number of family planning consultations. The names of the 19 chosen Reporting Units, along with the number of consultations and sterilizations, appear in Table A2. Figure 1 shows their locations (p. 11). To form Sample II, the largest health center was chosen from each Reporting Unit.

Table A2. Reporting Units, Sample II

\begin{tabular}{|c|c|c|c|}
\hline Reporting Unit & $\underline{\text { Department }}$ & $\underline{\text { Number of Consultations }}$ & Number of Sterilizations \\
\hline S. B. S. Comas & Lima & 24,396 & 125 \\
\hline S. B. S. Comas & Lima & 24,396 & 125 \\
\hline S. R. S. Lima Ciudad & Lima & 21,042 & 47 \\
\hline S. B. S. Rimac & Lima & 20,578 & 41 \\
\hline UTES Huamanga & Ayacucho & 12,157 & 96 \\
\hline Tingo María Network & Huánuco & 10,260 & 95 \\
\hline UTES San Román, Juliaca & Puno & 9,617 & 114 \\
\hline UTES Chincha & Ica & 5,252 & 133 \\
\hline S. R. S. Pasco & Pasco & 5,132 & 102 \\
\hline ZONADIS Camaná & Arequipa & 4,890 & 88 \\
\hline Aparicio Pomares Network & Huánuco & 4,001 & 76 \\
\hline UTES 4 Pacasmayo & La Libertad & 3,672 & 138 \\
\hline UTES 5 Huamachuco S. C. & La Libertad & 3,655 & 56 \\
\hline ZONADIS Aplao Castilla & Piura & 3,605 & 65 \\
\hline Panao Network & Huánuco & 3,002 & 43 \\
\hline S. B. S. Chancay & Lima & 2,850 & 90 \\
\hline Hospital de Apoyo Casma & Ancash & 2,342 & 50 \\
\hline UTES Pisco & Ica & 2,124 & 40 \\
\hline UTES Cangallo & Ayacucho & 1,476 & 73 \\
\hline
\end{tabular}


Sample III. The purpose here was to obtain a sample of rural health posts. Hence, Reporting Units pertaining to Metropolitan Lima $(\mathrm{N}=9$ ) were excluded from the list of Reporting Units that performed less than 40 sterilizations in 1998. Nineteen Reporting Units were randomly chosen, weighted for number of family planning consultations. The chosen Reporting Units, along with the number of consultations and sterilizations, appear in Table A3. Figure 1 depicts them on the map (p. 11). To form Sample III, information concerning the size of rural lealth posts within each Reporting Unit was obtained and one rural health post was ramdomly chosen per Reporting Unit, weighted for user population.

Table A3. Reporting Units, Sample III

\begin{tabular}{|c|c|c|c|}
\hline$\underline{\text { Reporting Unit }}$ & Department & $\underline{\text { Number of Consultations }}$ & $\underline{\text { Number of Sterilizations }}$ \\
\hline UTES Ica & Ica & 6,938 & 0 \\
\hline UTES Ica. & Ica & 6,938 & 0 \\
\hline S. B. S. Cañete-Yauyos & Lima & 6,384 & 6 \\
\hline S. B. S. Cañete-Yauyos & Lima & 6,384 & 6 \\
\hline UBASS Tocache & San Martín & 3,605 & 8 \\
\hline Hospital Apoyo Huari & Ancash & 3,535 & 36 \\
\hline UTES San Miguel & Ayacucho & 3,260 & 27 \\
\hline UTES Chucuito & Puno & 3,202 & 15 \\
\hline UTES Huanta & Ayacucho & 2,795 & 14 \\
\hline UTES Collao & Puno & 2,588 & 32 \\
\hline UTES San Francisco & Ayacucho & 2,511 & 33 \\
\hline UTES Sandia & Puno & 2,339 & 36 \\
\hline UBASS Ferreñafe & Lambayeque & 2,213 & 31 \\
\hline Hospital Apoyo Pomabamba & Ancash & 2,174 & 17 \\
\hline UTES 7 Santiago de Chuco & La Libertad & 1,801 & 39 \\
\hline UTES Puquio & Ayacucho & 1,684 & 22 \\
\hline Hospital de Apoyo Sihuas & Ancash & 1,675 & 20 \\
\hline Hospital de Apoyo Huarmey & Ancash & 1,645 & 29 \\
\hline UBASS Quimbiri & Cuzco & 1,386 & 11 \\
\hline
\end{tabular}




\section{APPENDIX B. LQAS METHODOLOGY}

\section{LQAS Applied to Individual Facilities}

Triage System. A three-part classification of lots was established in the first phase, as follows:

- Judge the facility as having adequate care if 95 percent or more of clients receive adequate care.

- Judge it inadequate if between 50 percent and 95 percent of clients receive adequate care.

- Judge it very inadequate if 50 percent of clients or less receive adequate care.

Figure B1. Operating-characteristics curve for LQAS 6:1 decision rule to assess individual facilities



6:1 Decision Rule. The sample size chosen was six cases per facility. A larger number of visits by simulated clients acting out the same client profile would have alerted providers to the presence of an evaluation and might have induced them to offer maximal performance instead of typical performance. The decision rule chosen from Valadez et al.,'s (1991) tables, 6:1, allowed for one error; i.e., if five or more clients received adequate care, the facility was classified as performing adequately (we concluded that the facility had reached the 95 percent standard). On the other hand, if more than one client failed to receive adequate care, we concluded that care was very inadequate. Because LQAS uses binomials, it can identify quality precisely at either end of the continuum: adequate or very inadequate. It is less sensitive to levels in the middle category (inadequate care).

Provider and Consumer Errors. The operating characteristics (OC) curve corresponding to the 6:1 rule, shown in Figure B1, allows us to identify the associated errors affecting providers and consumers. The horizontal axis represents the proportion of clients receiving adequate care. The vertical axis corresponds to the probability of accepting the lot. When 95 percent or more of the clients receive adequate services, the $6: 1$ decision rule will correctly identify 96.7 percent of the cases (specificity). The provider error, i.e., rejecting the lot when in fact 95 percent or more of the population of clients receive adequate care, is equal to $1-.967=.033$. When only 50 percent or less deliver adequate services, the 6:1 rule will incorrectly classify the clients as receiving adequate care 
only 10.9 percent of the time (consumer error). Sensitivity is equal to $100.0-10.9=89.1$ percent.

\section{LQAS Applied to Sample of Facilities}

Triage System. The second phase entailed the sample of facilities. The three-part triage system in this phase was as follows:

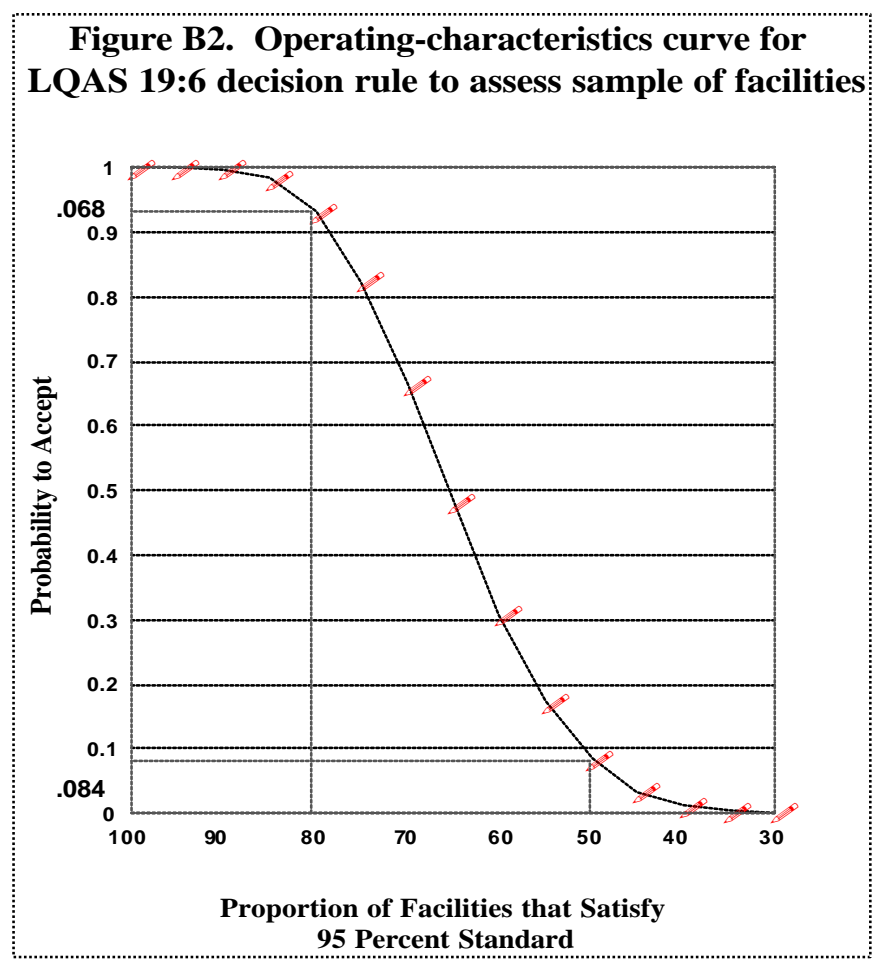

- Judge the sample of facilities as having adequate care if 80 percent or more of the facilities satisfy the 95 percent standard for individual facilities.

- Judge it inadequate if between 50 percent and 80 percent of the facilities satisfy the 95 percent standard for individual facilities.

- Judge it very inadequate if 50 percent of the facilities or less satisfy the 95 percent standard for individual facilities.

Decision Rule and Errors. The sample size was 19 facilities, and the decision rule selected was 19:6. That is, up to six errors were tolerated. Figure B2 offers the corresponding OC curve. The probability of rejecting the lot when in fact 80 percent or more of the facilities offer adequate care is .068 ; i.e., specificity $=$ 93.2 percent. The probability of accepting the lot when in fact only 50 percent or less of the facilities offer good care is .084; i.e., sensitivity $=91.6$ percent. 


\section{APPENDIX C. TRAINING AND SUPERVISION OF SIMULATED CLIENTS}

\section{Selection Criteria}

Hospitals were to be visited by women who sought sterilization services. Health centers were to be visited by younger women who sought family planning counseling. Thus, two cohorts of candidates to perform as simulated clients were recruited in a dynamic process and received one week of training. The first selection criteria concerned the candidates' age and obstetric history. Sample I required healthy women aged 30-40 with more than one child. Sample II required healthy women aged 20-30 with one child. The second step involved standardized tests of general cognitive ability, immediate memory, and family planning knowledge. The third requirement was to learn to enact a client profile and use the corresponding checklist. This was evaluated during training. A few simulated clients were dismissed during or after completion of training because they would not accept a pelvic examination or were found to have medical conditions that might contraindicate sterilization.

\section{Instrument Adjustment}

The profiles and corresponding checklists were discussed with the MOH and USAID/Peru and adjusted during training. The candidates selected to perform as simulated clients role-played in the classroom visits to facilities and identified a number of problems in the checklists. Finally, they identified further needs for adjustments as they implemented the Service Test at several hospitals and health centers in Lima as part of their training.

\section{Supervision}

In the field, supervisors debriefed each simulated client after their first visits to facilities to ensure that they were acting out the client profile and filling out the checklist properly. The simulated clients performed their task knowing that the supervisor would later visit the facility to revise the clinic history corresponding to their case and verify specific aspects of the consultation.

\section{Ethics}

During training, the simulated clients were informed in detail about the clinical procedures they might be exposed to in hospitals or health centers, including possible pelvic examinations, and were given the choice of withdrawing. Providers were not advised in advance about the visits from simulated clients since otherwise their service behavior might have been distorted. To comply with ethical requirements of the project, project supervisors performed post hoc visits to providers to explain the nature of the study, give them assurances concerning the confidentiality of the data obtained, and provide feedback regarding the handling of the case. The reactions of providers were rather positive. They showed an active interest in the feedback and said they would like to participate in similar processes more frequently. 


\title{
APPENDIX D. TRAINING AND SUPERVISION OF INTERVIEWERS
}

\author{
Follow-Up of Clients Sterilized at Hospitals
}

Instrument and Training of Interviewers. The questionnaire designed for the home follow-up of patients sterilized at hospitals focused on their memories of the client-provider interaction process and was tested in early July. The training of interviewers took place in Lima on July 19-21. The questionnaire was discussed with the $\mathrm{MOH}$ and USAID/Peru and adjusted during training. The candidates selected to perform as interviewers role-played in the classroom visits to facilities and identified a number of problems in the questionnaire. Finally, they identified further needs for adjustments as they implemented real interview in Lima as part of their training

Ethics. Clients were to be asked for their informed consent to participate in the interview and given the option to reject it without personal consequences. They were to be assured that the information would be treated confidentially. At the end of the interview, they were asked to consent on a home visit by a supervisor.

Supervision. In the field, supervisors debriefed each interviewer after their first visits to ensure they were performing the task properly. The interviewers performed the task knowing that the supervisor could later re-interview the client at his/her home. In fact, one case of each six per facility were re-interviewed by project supervisors.

\section{Exit Interviews at Health Centers}

Interviewer Training and Instrument Adjustment. The training of 22 interviewers took place in Lima on 24 August 1999. The questionnaire was discussed with the MOH and USAID/Peru in July and adjusted during training. The candidates selected to perform as interviewers role-played in the classroom visits to facilities and identified a number of problems in the questionnaire. Finally, they identified further needs for adjustments as they implemented the exit interview at several health centers in Lima as part of their training.

Ethics. Clients were to be asked for their informed consent to participate in the interview and given the option to reject it without personal consequences. They were to be assured that the information would be treated confidentially. At the end of the interview they were asked to consent to a home visit by a supervisor. Only if they agreed the interviewer obtained the client address.

Supervision. In the field, supervisors debriefed each interviewer after their first visits to facilities to ensure that they were performing the task properly. The interviewers performed their task knowing that the supervisor could later re-interview the client at her/his home. One case of each six per facility were re-interviewed by project supervisors.

\section{Users of Rural Health Post Services}

Instrument and Training of Interviewers. The questionnaire designed for the home follow-up of users of rural health post family planning services was similar to that used in the exit interviews. The questionnaire was discussed with the $\mathrm{MOH}$ and USAID/Peru and pretested in Lima and provinces. The training of interviewers started in Puno on July 19. Other groups of interviewers 
were trained subsequently in Lima, Chiclayo, and Ica.

Ethics. Clients were to be asked for their informed consent to participate in the interview and were given the option to reject it without personal consequences. They were assured that the information would be treated confidentially. At the end of the interview, they were asked to consent on a home visit by a supervisor.

Supervision. In the field, supervisors debriefed each interviewer after their first visits to ensure they were performing the task properly. The interviewers performed the task knowing that the supervisor could later re-interview the client at his/her home. Supervisors pérformed one reinterview per each six cases per facility. 


\section{APPENDIX E. INTERINDIVIDUAL VARIATION WITHIN FACILITIES}

The specific provider behaviors that failed to meet the LQAS standard despite a high frequency of occurrence reveal a relative lack of consistency in provider behavior within facilities. Let us, for example, take the item "Provider told client that the union of spermatozoid and ovum is prevented (by tubal ligation)", observed in 82 percent of the 114 cases at hospitals, which failed to meet the LQAS standard. Table E1 shows the distribution of cases in relation to this item and also the distribution of an item which did meet the LQAS standard despite its lower raw percentage ("The opening of the clinic history was free of charge", 74 percent). The latter item has a considerably higher frequency of extreme scores ("6s", "5s", "0s", or "1s") - a total of 32 - than intermediate scores ("2s", "3s", or "4s") - a total of 6 . Therefore, the trend was for all or almost all the providers within the facility either to exhibit or fail to exhibit the behavior. In the case of the first item, the number of extreme scores (a total of 22) was similar to that of intermediate scores (a total of 16). Here the trend was less discernible. Thus, despite the fact that more individual cases reported expected provider behavior 1 (93, or 82 percent) than expected provider behavior 2 (84, or 74 percent), more hospitals met the LQAS standard for expected behavior 2 (16 hospitals) than expected behavior 1 (11 hospitals). This contrast can be understood with the help of the concept of normative behavior. Whether or not payments were requested of the simulated client was a reflection more of

Table E1. Frequency distribution of two Service Test items

\begin{tabular}{|c|c|c|c|c|c|c|c|c|c|}
\hline \multirow[b]{3}{*}{ Hospital } & \multicolumn{4}{|c|}{$\underline{\text { Items }}$} & & \multicolumn{4}{|c|}{$\underline{\text { Items }}$} \\
\hline & \multicolumn{2}{|c|}{$\underline{\text { Action Mechanism }}$} & \multicolumn{2}{|c|}{ Paid Clinic History } & \multirow[b]{2}{*}{ Hospital } & \multicolumn{2}{|c|}{$\underline{\text { Action Mechanism }}$} & \multicolumn{2}{|c|}{ Paid Clinic History } \\
\hline & No & Yes & No & Yes & & No & Yes & No & Yes \\
\hline 1 & 0 & 6 & 1 & 5 & 11 & 0 & 6 & 5 & 1 \\
\hline 2 & 3 & 3 & 6 & 0 & 12 & 1 & 5 & 6 & 0 \\
\hline 3 & 0 & 6 & 5 & 1 & 13 & 2 & 4 & 5 & 1 \\
\hline 4 & 2 & 4 & 5 & 1 & 14 & 0 & 6 & 5 & 1 \\
\hline 5 & 0 & 6 & 1 & 5 & 15 & 0 & 6 & 5 & 1 \\
\hline 6 & 0 & 6 & 6 & 0 & 16 & 0 & 6 & 4 & 2 \\
\hline 7 & 2 & 4 & 6 & 0 & 17 & 3 & 3 & 6 & 0 \\
\hline 8 & 2 & 4 & 6 & 0 & 18 & 1 & 5 & 4 & 2 \\
\hline 9 & 2 & 4 & 3 & 3 & 19 & 0 & 6 & 5 & 1 \\
\hline 10 & 3 & 3 & 0 & 6 & Total & 21 & 93 & 84 & 30 \\
\hline
\end{tabular}


the policy of the facility than of the decision of the individual provider. In contrast, more room for inter-individual variation within facilities was revealed by information-giving provider behavior. 


\section{APPENDIX F. CASE STUDIES}

Data collection aimed at completing 114 interviews about the process of VSC service reception. One-hundred seventeen interviews were initiated and three were not completed owing to the fact that the client showed during the first part of the interview that she was not aware of having been sterilized. One of the cases pertained to a woman who, under re-interview by a project supervisor, confessed that she had asked for, and received, VSC services but had preferred not to disseminate this information in the initial household interview. Another was a misclassification of the Family Planning Coordinator who offered the list of sterilized patients at one hospital. The project supervisor discovered in the original list of patients receiving services that the name of the 23 year-old patient appeared associated with a cesarean intervention, not with VSC.

The third case remains in a complex status. According to the woman, she was in the eight month of pregnancy and was brought to the hospital by her brothers in a semi state of consciousness. Pre-eclampsia was diagnosed and a cesarean procedure was performed successfully. The brothers signed all the authorizations requested by the physicians. The woman says that she does not wish to have more children ever but does not need contraception at this moment for she is separated from her husband. She received VSC counseling during her prenatal visits but would be afraid of a tubal ligation and would prefer to use a reversible method. Yet, her name was in the hospital's list as that of a patient who received both cesarean and VSC procedures. At the moment of the inquiry by the project supervisor, the clinic history was not available; it had been misplaced somewhere within the hospital. Later the Family Planning Coordinator called the supervisor saying that the clinic history had been found and that it showed that only the cesarean procedure had been performed, not the tubal ligation. To justify the presence of the patient's name in the list of sterilized patients, the Family Planning Coordinator said that the woman was considering VSC during her prenatal counseling, had signed the first VSC-consent form, and was in the list of prospective tubal ligations. She assumes that the procedure did not materialize because the patient could not sign the second VSC-consent form given the obstetric emergency. Another possibility is that the tubal ligation in fact was performed and the physician, lacking a second VSC-consent signature, omitted referring to it in the clinic history to avoid legal responsibility.

Finally, a death was registered in the re-interview period that involved a randomly sampled client (from each six) interviewed after receiving services at a given facility. The interviewer wrote a comment in the questionnaire concerning the ill health of the woman at the moment of the interview in her home, just discharged from the hospital one month after giving birth. She had asked for the sterilization and received family planning counseling prior to her partum, including information about reversible methods. The VSC procedure took place in the immediate postpartum. The physician had told her that her life was in risk and that hers was a good decision since having yet another child would be very dangerous. She said that she had been "very swollen" when she went to the hospital and that her blood pressure during delivery had been "190". Weeks later, a project supervisor sought to re-interview the woman and found that she was deceased. Her father informed that she had been a diabetic who suffered high blood pressure and had given birth undergoing a severe eclampsia. The project supervisor interviewed a nurse-obstetrician who was familiar with her case at the provincial hospital, who confirmed that the woman had given birth in poor condition and weeks later had to be taken to hospitals in the departmental capital and then Lima. 